\title{
Sevilla: una experiencia exitosa de promoción de la movilidad en bicicleta en el Sur de Europa
}

\section{Ricardo Marqués Sillero *}

\section{Resumen}

En apenas cuatro años la ciudad de Sevilla ha pasado de una participación marginal de la bicicleta en el conjunto de la movilidad urbana a cotas de participación en torno al 6\% del reparto modal global de la ciudad. Éste ha sido el resultado de un proceso social y de unas políticas activas de promoción de la bicicleta que se analizan a lo largo de este artículo con el ánimo de identificar cuales han sido los factores determinantes de dicho éxito que podrían, en su caso, inspirar actuaciones similares en otras ciudades. Se analizan también las posibilidades de extensión de esta experiencia a otros ámbitos y en especial a la corona metropolitana de Sevilla, donde la participación de la bicicleta en el reparto modal es todavía muy escasa.

\section{Palabras clave}

Movilidad; Bicicleta; Ciclismo Urbano; Sostenibilidad Urbana.

\section{Abstract: Seville: a successful experience of promotion of the mobility in bicycle in Europa's South}

Along no more than four years the city of Sevilla has evolved from a marginal participation of cycling in the urban mobility to participation rates around $6 \%$ of global modal sharing in the city. This has been the result of a social process and of some active policies aimed to the promotion of urban cycling, which are analyzed along this paper. Our main purpose is to identify the factors which have determined this success and that would, eventually, encourage similar actions in other cities. We also analyze the possibilities for extending this experience to other anvironments, specifically to the external conurbation of Sevilla, where the participation of cycling in the modal share is still marginal.

\section{Key words}

Mobility, Bycicle; Urban Cycling; Urban Sustainability 


\section{Introducción: La bicicleta en el contexto de la movilidad metropolitana}

Tras años de ostracismo, la bicicleta comienza a ser considerada una alternativa real de movilidad sostenible en las ciudades (Sanz, 1996). Aparte de las ciudades "históricas", como Amsterdam o Copenhague, muchas otras ciudades a lo largo del Planeta elaboran en la actualidad planes de fomento de la movilidad ciclista, entre ellas ciudades tan emblemáticas para la cultura del automóvil como Chicago (City of chicago, 2006), Nueva York (New York city, 1997) o París (Mairie de Paris, 2010).

Un estudio bastante completo de la situación en España, aunque algo desfasado ya dada la rapidez con la que se desenvuelven los acontecimientos, puede encontrarse en Molinero (2007). En Sevilla, en el corto periodo de tiempo que va de junio de 2006 a noviembre de 2009, se construyen $120 \mathrm{~km}$ de vías ciclistas y el número de ciclistas en día laborable se multiplica por un factor de 10 [sic], pasando de una participación marginal en el reparto modal de la ciudad, a valores en torno al $6 \%$ del total de los desplazamientos urbanos (Ayuntamiento de Sevilla, 2010). Se trata de una experiencia sin precedentes a escala mundial, especialmente por el corto periodo de tiempo en que se ha producido. La celebración en Sevilla del Congreso Mundial Velo-City $2011^{1}$ ha sido, en parte, debida al interés que dicha experiencia ha despertado entre los expertos en movilidad urbana de todo el mundo. La descripción y el análisis de esta experiencia, estableciendo sus causas objetivas, así como sus fortalezas y debilidades, es el objetivo de este artículo.

Antes que nada, sin embargo, es preciso contextualizar apropiadamente los hechos. La ciudad de

${ }^{1}$ Sevilla 23-25 de marzo de 2011. <http://www.velocity2011.com/>
Sevilla tiene en la actualidad una población aproximada de 700.000 habitantes, siendo el núcleo central de una conurbación que agrupa a otros tantos vecinos, distribuidos por un total de 45 municipios, que conforman su corona metropolitana (Consorcio de Transporte, 2007). Así pues, Sevilla es el centro de un área metropolitana habitada por aproximadamente 1.400 .000 personas que se reparten a partes iguales entre su núcleo central y la corona metropolitana. A lo largo de los últimos años esta proporción ha venido creciendo a favor de la corona metropolitana, que ha ido absorbiendo la práctica totalidad del crecimiento de la población del área, en un proceso de conurbación aparentemente imparable. La estructura de la movilidad en el área metropolitana ha reflejado esta transformación, evolucionando hacia un modelo dominado por el coche privado y en el que la disminución porcentual tanto de los desplazamientos no motorizados (a pie y en bicicleta) como de los desplazamientos en transporte público ha sido la tónica general, tal y como puede observarse en la Figura 1.

El análisis pormenorizado de las causas de esta evolución es algo que excede los límites de este artículo. Sin embargo, es evidente que el ya citado proceso de conurbación está en la raíz de los profundos cambios que revela la Figura 1. Este hecho se puede deducir sin más del análisis comparativo de la movilidad en el núcleo central y en la corona metropolitana ${ }^{2}$, donde se observa que la movilidad en el núcleo central (Sevilla) se ha mantenido en valores similares a los de la movilidad metropolitana a mediados de la década de los 90, mientras que en la corona el uso del

\footnotetext{
${ }^{2}$ Por movilidad del núcleo central entendemos todos los desplazamientos internos al municipio de Sevilla, mientras que por movilidad de la corona metropolitana entendemos el resto de la movilidad metropolitana, incluyendo los desplazamientos entre Sevilla y los municipios de su entorno.
} 
automóvil privado y de la motocicleta ha "explotado" hasta valores en torno al $65 \%$ del total de los desplazamientos.

Puede observarse también en la gráfica como la movilidad en bicicleta empezaba ya a despuntar en 2007 en el núcleo central, como consecuencia del proceso mencionado al comienzo de esta sección, sin que se aprecie una evolución similar en la corona metropolitana.

$$
\begin{array}{r}
20 \% \\
10 \% \\
0 \%
\end{array}
$$

Figura 1. Evolución del reparto modal en el área metropolitana de Sevilla. Fuente: elaboración propia a partir de las sucesivas encuestas domiciliarias de movilidad (Consorcio de Transportes, 2007), (A Contramano, 2011).

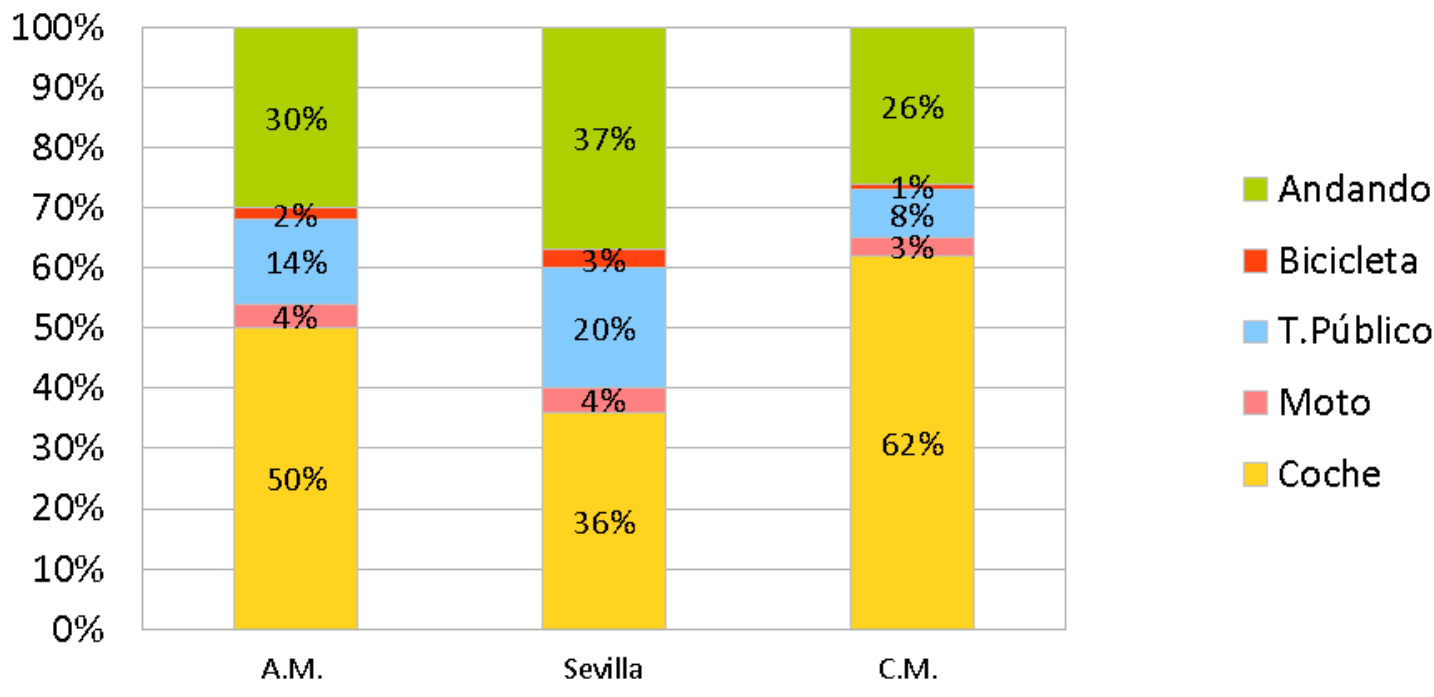

Figura 2. Distribución modal en el conjunto del área metropolitana (AM), en su núcleo central (Sevilla) y en la corona metropolitana (CM). Fuente: Encuesta domiciliaria de movilidad (Consorcio de Transportes, 2007).

Nos encontramos pues, en lo que a la bicicleta respecta, ante un fenómeno que se desarrolla exclusivamente en el núcleo central del área metropolitana, como consecuencia de unas políticas muy concretas desarrolladas en dicho área, principalmente por el Ayuntamiento de Sevilla, sin apenas incidencia en el resto de la conurbación. Lo que no quiere decir, como veremos al final de este artículo, que la bicicleta no pueda, si se desarrollan las políticas adecuadas, llegar a jugar un papel de primordial importancia en la reorientación de la movilidad de la corona metropolitana hacia patrones más sostenibles. 


\section{Breve descripción cronológica}

Si bien la ciudad de Sevilla contaba en el año 2003 con aproximadamente $12 \mathrm{~km}$ de vías ciclistas, inconexas y de escasa utilidad práctica, la historia que nos ocupa empieza realmente tras la formación del primer gobierno municipal de coalición PSOE-IU, en la primavera de 2003, con la puesta en marcha de la primera experiencia de Presupuestos Participativos en la ciudad. A principios de 2004 la demanda de una red ciudadana de carriles-bici, diseñada para satisfacer las necesidades de movilidad cotidianas, es la propues-

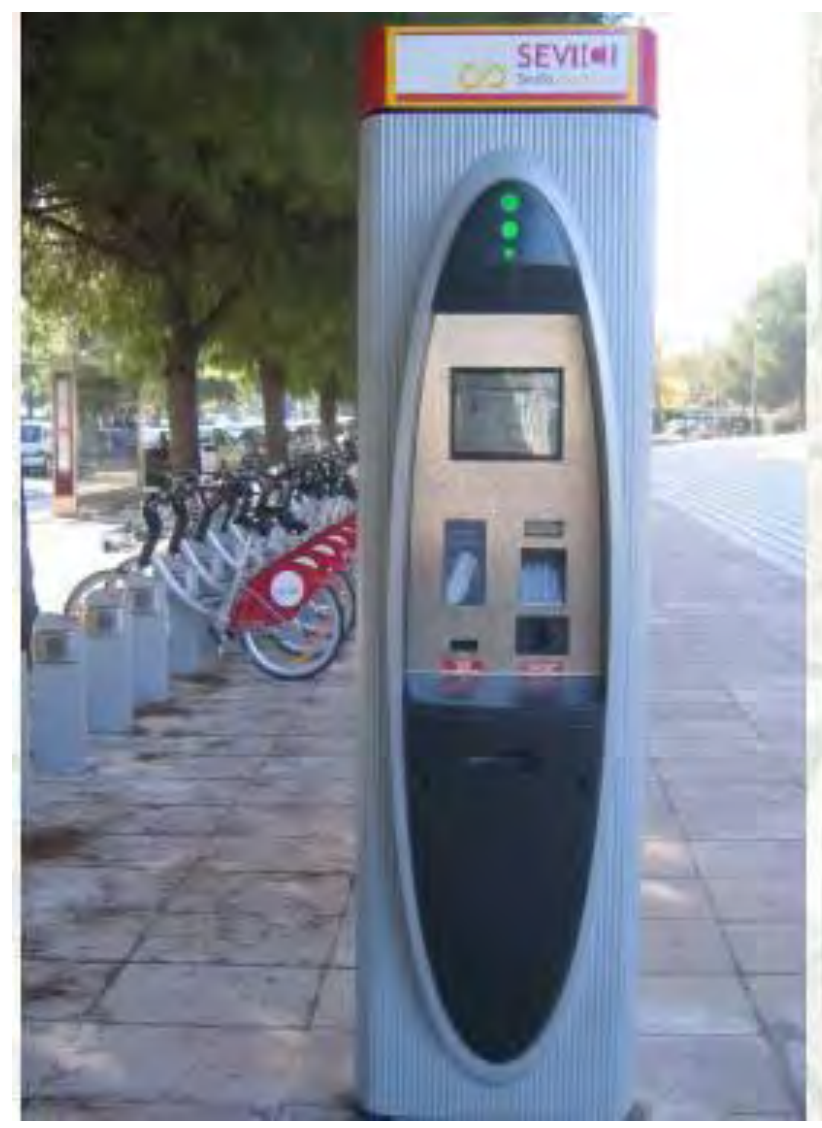

ta mas votada entre los participantes en dicho proceso. En consecuencia, en ese mismo año de 2004, se inicia la elaboración del documento de "Bases y Estrategias para la Integración de la Bicicleta en la Movilidad Urbana de Sevilla", que define una primera red básica de $77 \mathrm{~km}$ de vías ciclistas, elaboradas según criterios de conectividad entre los principales barrios de la ciudad y los principales centros de atracción de viajes: centros educativos, intercambiadores de transporte, zonas comerciales y de ocio, polígonos industriales, etc.

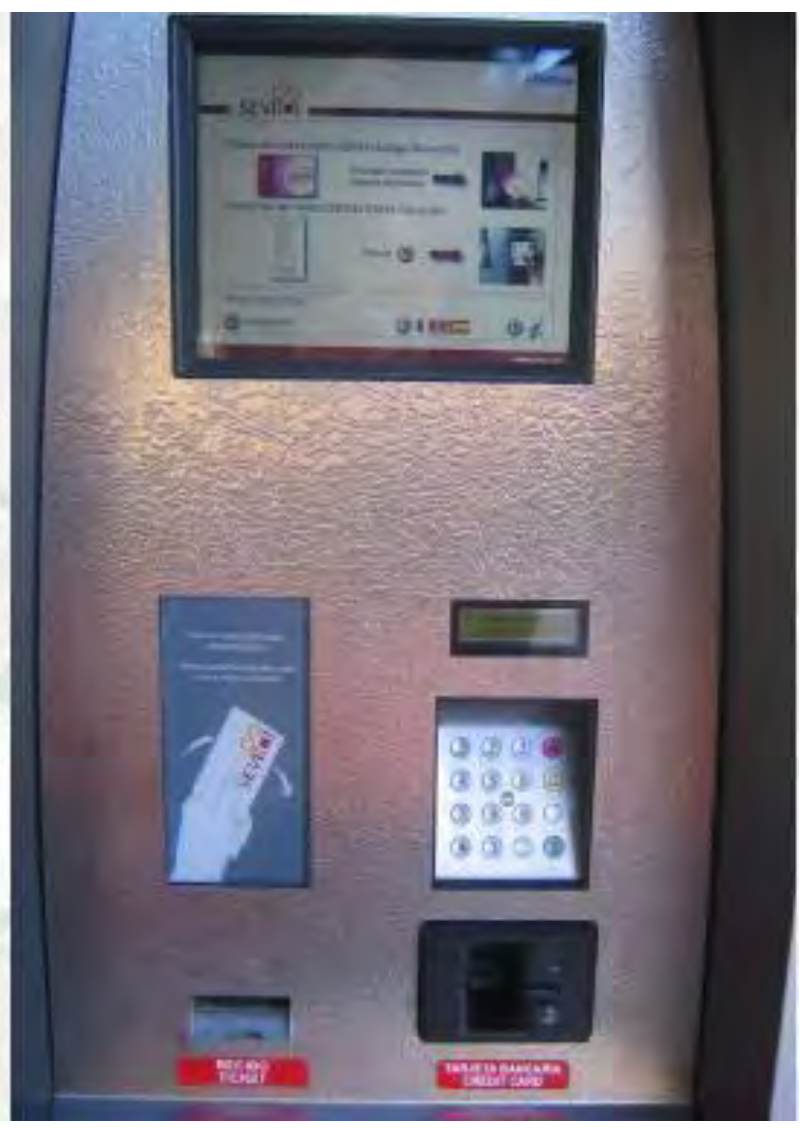

Figura 3. Imagen de una estación de Sevici con el poste de control en primer plano y detalle del dispositivo de préstamo.

La redacción del documento finaliza en el año 2005, año en el que comienza la redacción de los Proyectos de Ejecución de los 8 itinerarios ${ }^{3}$ en los que se subdivide dicha red.

El 19 de julio de 2006 se aprueba definitivamente

${ }^{3} \mathrm{La}$ red se subdivide en itinerarios a efectos puramente constructivos, sin que ello suponga ninguna diferencia de diseño observable para el usuario. el nuevo Plan General de Ordenación Urbana (PGOU) de Sevilla, que incluye igualmente entre sus determinaciones la creación de una red de vías ciclistas para la ciudad con objeto de transporte. La aprobación del PGOU supone, entre otras cosas, la disposición de fondos para la realización de sus determinaciones, por lo que el 26 de agosto de 2006 comienzan las obras de 
ejecución de los 8 itinerarios citados que conforman la "Red Básica de Vías Ciclistas" de Sevilla, con un presupuesto de 18 millones de euros. Es de destacar que esta Red Básica se ejecuta con carácter de viario estructurante de la ciudad, lo que la dota de un nivel de protección inédito hasta la fecha en España en lo que a vías ciclistas se refiere. Las obras de esta primera red finalizan en diciembre de 2007 y en el ínterin, en marzo de 2007, se aprueba el "Plan Director para el Fomento del Transporte en Bicicleta en Sevilla 20072010" que incluye una serie de actuaciones complementarias de fomento, como el desarrollo de caminos escolares, medidas para el fomento de la bicicleta en las empresas municipales, convenios con otros organismos, etc... y al mismo tiempo se desarrollan planes complementarios para dotar a la ciudad con un número adecuado de aparcamientos para bicicletas en la vía pública ${ }^{4}$.

En agosto de 2007 comienza la implantación de un sistema público de bicicletas (Sevici) que en su fase final incluye un total de 2.500 bicicletas en 250 estaciones de préstamo automáticas repartidas por toda la ciudad ${ }^{5}$, conforme al mismo sistema ya existente en otras ciudades como Lyon o, posteriormente, París. El sistema es gestionado por la multinacional especializada en publicidad estática J.C.Decaux y se establece como contraprestación sin coste alguno (excepto, claro está, la merma de ingresos correspondiente) por la concesión de elementos de publicidad estática en la ciudad. De cara al usuario se ofrece un servicio ininterrumpido las 24 horas del día con dos tipos de abono, semanal y anual, pensados respectivamente para turistas y vecinos de Sevilla y su área metropolitana ${ }^{6}$. La primera $1 / 2$ hora de uso

${ }^{4}$ La documentación citada puede consultarse en $<$ http://www.sevilla.org/sevillaenbici/>

${ }^{5}$ Estando previsto ampliar el servicio a 2900 bicicletas y 290 estaciones en los próximos años.

${ }^{6}$ o se exige ser vecino del municipio de Sevilla para asociarse, lo que, junto a la ubicación de estaciones en los principales terminales del transporte público, favorece el uso intermodal de Sevici. es gratuita, pudiendo prorrogarse indefinidamente mediante sucesivos cambios de bicicleta, existiendo una tarifa específica para tiempos de uso superiores de la misma bicicleta.

Entre julio y noviembre de 2008 se lleva a cabo la redacción de los proyectos de ejecución de la Red Complementaria de vías ciclistas de Sevilla, de $43 \mathrm{~km}$ de longitud, cuyas obras comienzan en junio de 2009 con un presupuesto de 12 millones de euros que son financiados con cargo al "Plan 8000 " de apoyo a las comunidades locales. Las obras de esta segunda fase finalizan en junio de 2010, quedando de ese modo configurada la red de vías ciclistas con un total de $120 \mathrm{~km}$ de carriles bici bi-direccionales, que posteriormente son objeto de un plan de mejora con un presupuesto total de 2 millones de euros, lo que arroja un presupuesto total de 32 millones de euros para el conjunto de la red. Red que deberá luego ser complementada con actuaciones locales a nivel de barrio, con cargo a los presupuestos específicos del Plan de Barrios de la ciudad, alguna de las cuales ya se han realizado o se están realizando con mayor o menor fortuna.

De modo simultáneo se procede a la redacción de la Ordenanza Municipal de Circulación de Peatones y Ciclistas, que entra en vigor en mayo de 2008 y que establece el marco jurídico que ordena el uso de las infraestructuras mencionadas y, en general, la circulación del creciente número de ciclistas por la ciudad.

Para la gestión de todo este proceso se crea un organismo específico: la Oficina de la Bicicleta, dependiente de la Delegación de Infraestructuras para la Sostenibilidad y con sede en la Gerencia de Urbanismo, con una plantilla de 18 trabajadores/as. La Oficina de la Bicicleta es la encargada de coordinar la redacción de los sucesivos proyectos de obra, así como de su supervisión. Asimismo coordina la redacción del mencionado "Plan Director" y es la encargada del desarrollo de 
sus programas específicos, incluyendo los convenios que se establecen entre el sistema de bicicletas públicas municipal Sevici y las diferentes empresas municipales, así como con la Universidad de Sevilla, para fomentar su uso. Igualmente participa en la redacción de la Ordenanza Municipal de Circulación de Peatones y Ciclistas.

Para fomentar la participación tanto de los usuarios como de los principales actores del mundo de la bicicleta se crea la Comisión Cívica de la Bicicleta, que a lo largo de todo este proceso se reúne periódicamente para recibir información sobre los planes de actuación, debatirlos y hacer sugerencias. Participan en dicha Comisión asociaciones de peatones y ciclistas, empresas del mundo de la bicicleta, técnicos municipales y, en general, cuantos actores se consideran relevantes para el desarrollo del Plan Director.

No sería justo terminar esta sección sin mencionar una serie de actuaciones pioneras que sin duda han contribuido a allanar el camino hacia la situación actual. Mención especial merece el proyecto Bus+Bici del Consorcio de Transportes de Sevilla, que se inaugura en septiembre de 2006 en la Estación Metropolitana de Autobuses de Plaza de Armas (Sevilla) y que constituye la primera experiencia pública de fomento de la intermodalidad bicicleta-transporte público de Andalucía. El proyecto consiste en el préstamo gratuito a los usuarios de las líneas de autobús metropolitano que llegan a dicha Estación de una bicicleta urbana para sus desplazamientos por Sevilla. El sistema cuenta en la actualidad con 172 bicicletas y se complementa con un aparcamiento de uso libre en el interior de la Estación. El sistema alcanzó un máximo de 4.000 préstamos durante el mes de diciembre de 2010 (Consorcio de Transportes, 2010), lo que supuso un total aproximado de 16.000 desplazamientos en bicicleta durante dicho mes. El éxito de este sistema de préstamo intermodal fue sin duda uno de los precedentes que dieron impulso a la instalación del sistema de bicicletas públicas municipal.

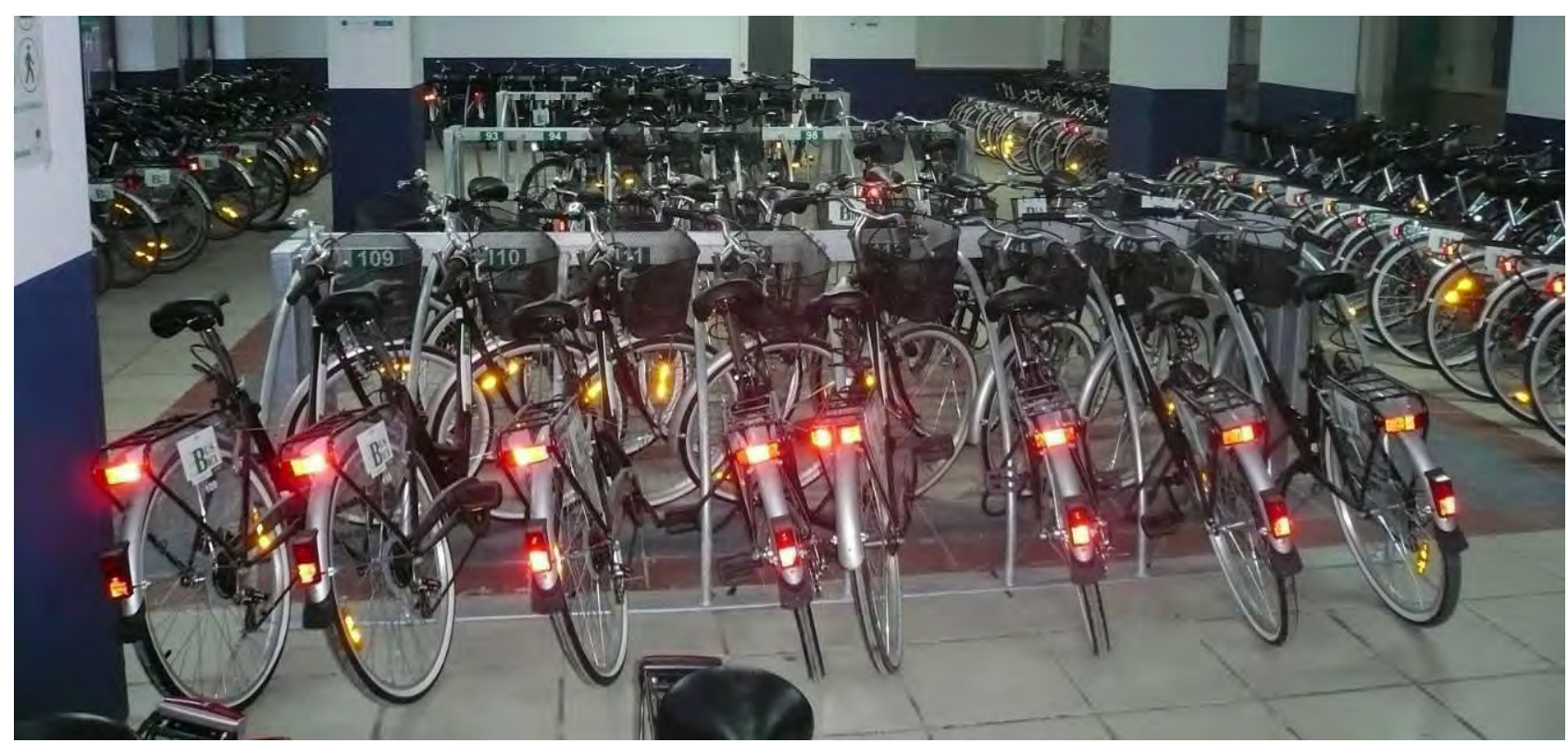

Figura 4. Bicicletas de proyecto Bus+Bici aparcadas en Plaza de Armas.

Aún más importante ha sido el papel jugado por la Universidad de Sevilla. Con un total de aproximadamente 86.000 miembros entre estudiantes, profesores y personal de administración y servi- cios, la comunidad universitaria asciende aproximadamente al $12 \%$ de la población del municipio de Sevilla. Debido en parte a su estructura a base de edificios dispersos por la trama urbana de la 
ciudad, la Universidad ha mantenido una cierta tradición de uso de la bicicleta, que se ha visto favorecida por el desarrollo paulatino, desde la década de los 90, de un sistema de aparcamientos vigilados de bicicletas en sus facultades y escuelas. Este sistema ofrece en la actualidad un total aproximado de 1.800 plazas de aparcamientos para bicicletas de acceso restringido, más otras 750 de acceso libre (Marqués, 2009) que son utilizadas masivamente por los universitarios. Estas facilidades de aparcamiento posibilitaron el mantenimiento de aquella tradición, hasta el punto de que en un estudio del año 2002 (A Contramano, 2002) se contabilizaron un total aproximado de 1.000 desplazamientos diarios en bicicleta en una de las vías de acceso a uno de sus Campus, un nivel de uso comparable en orden de magnitud al actual, aunque inferior.

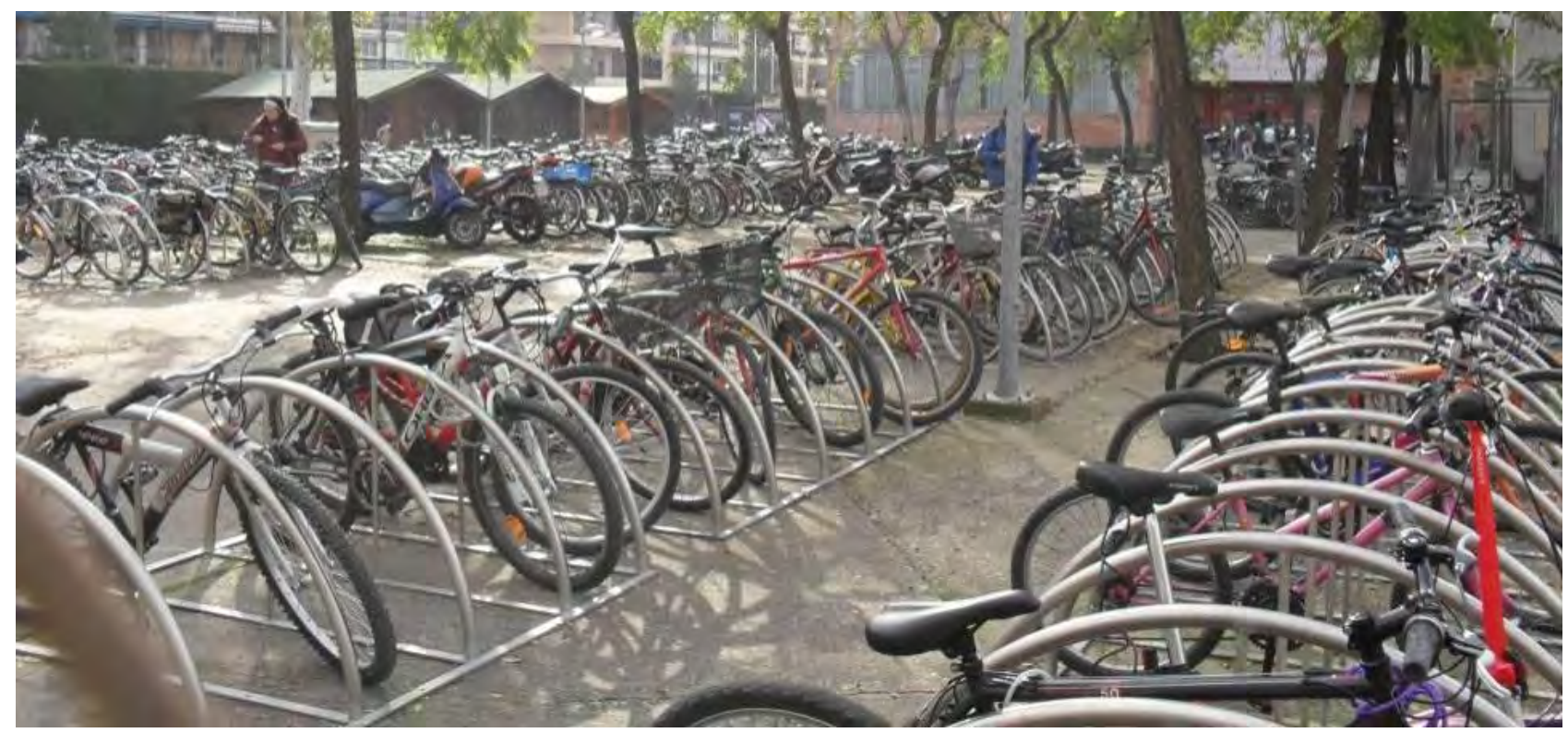

Figura 5. Bicicletas en uno de los aparcamientos de acceso restringido de la Universidad de Sevilla.

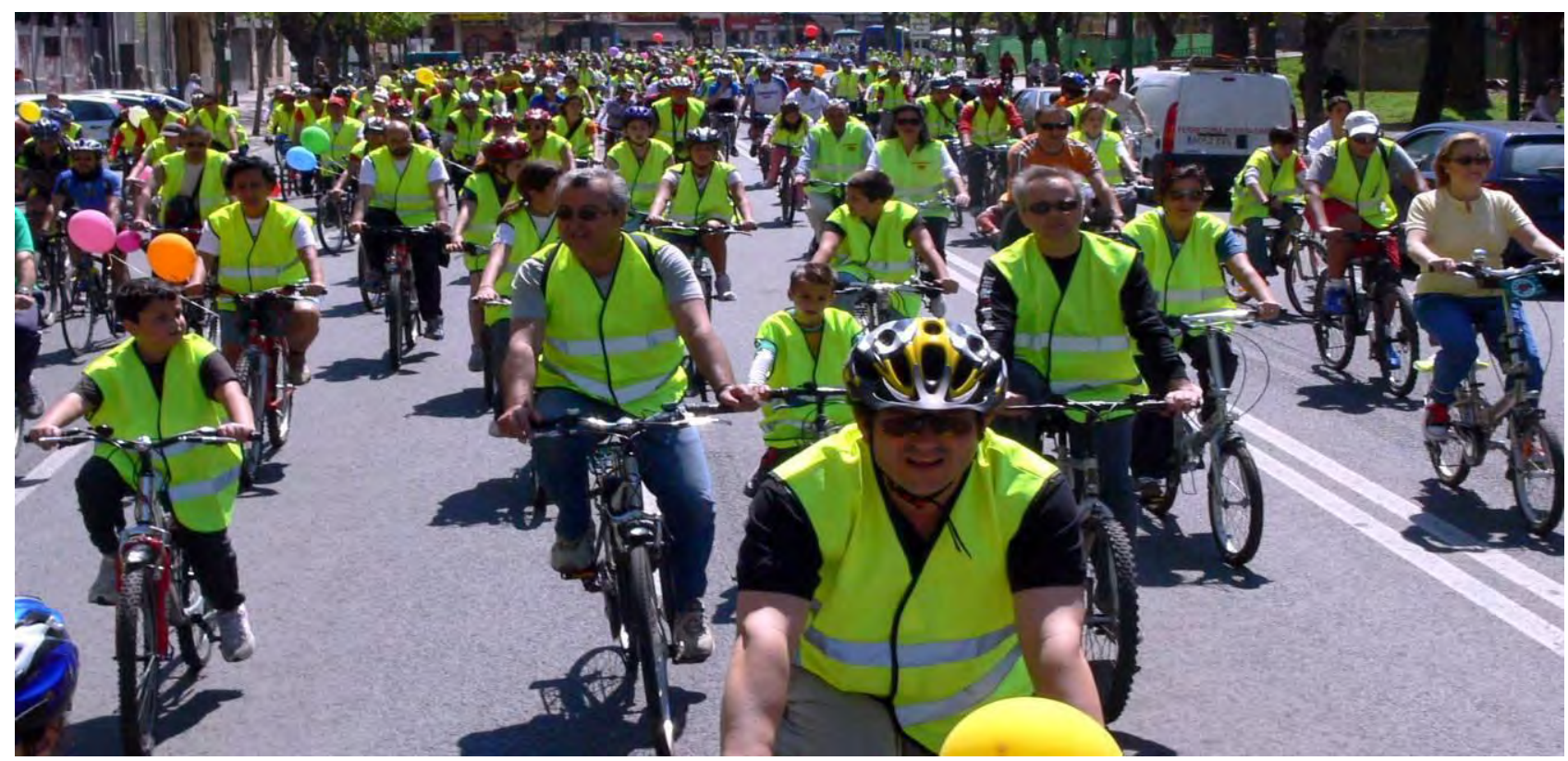

Figura 6. Participantes en el "X Día Metropolitano de la Bici” (2007). Masiva manifestación de apoyo a la creación de una red de carriles-bici en el área metropolitana de Sevilla, organizada por "A Contramano". 
Tras el inicio del Plan Director, la Universidad de Sevilla se suma a las actuaciones de fomento de la movilidad en bicicleta con una serie de actuaciones que se engloban en su Sistema Integral de Fomento de la Bicicleta (SIBUS) ${ }^{7}$, y que incluyen convenios con Sevici para favorecer al acceso al sistema de los universitarios y un sistema propio de préstamo de bicicletas (400 en la actualidad) (Marqués, 2009).

Finalmente, habría que mencionar la existencia en Sevilla, desde el año 1987, de una asociación de usuarios urbanos de la bicicleta, "A Contramano: Asamblea de Ciclistas de Sevilla", que a lo largo de todos esos años y hasta la fecha se ha mostrado muy activa en la defensa de la movilidad urbana sostenible en general y en bicicleta en particular, organizando movilizaciones ciudadanas, elaborando proyectos y participando activamente en todos los instrumentos del planeamiento asociados a la movilidad municipal y metropolitana.

En resumen, y con independencia de la opinión que merezcan las actuaciones reseñadas, es evidente que no han partido de cero, sino que han surgido de un caldo de cultivo previo. Es también evidente que no han sido fruto de la improvisación o de la casualidad, sino que han respondido a la existencia de una clara determinación política y a un plan coherente que ha contado en todo momento con el consenso de los usuarios, así como con la colaboración de las instituciones ciudadanas más interesadas en el fomento de la movilidad urbana en bicicleta, como son los casos citados del Consorcio de Transportes o la Universidad de Sevilla.

\section{Características principales de la red de vías ciclistas}

Ya hemos mencionado que tanto la Red Básica

\footnotetext{
${ }^{7}<$ http://bicicletas.us.es>

${ }^{8}<$ http://www.acontramano.org/>
}

como la Red Complementaría de vías ciclistas obedecen a un diseño unificado, basado en criterios de continuidad y conectividad con los principales centros de generación y atracción de viajes $^{9}$. Las vías ciclistas discurren además por las principales avenidas de la ciudad, lo que ayuda a evidenciar su carácter de viario estructurante.

Estas características de uniformidad, continuidad y conectividad han sido reforzadas por el diseño de las propias vías ciclistas, cuyas características más sobresalientes son:

- Bi-direccionalidad.

- Segregación del tráfico rodado.

- Pavimento y color uniformes en toda la red.

El carácter bi-direccional de las vías ciclistas está en relación con su carácter segregado y obedece también a la determinación de dotar a los ciclistas de mayor visibilidad social, permitiendo además una mayor economía en las obras y un considerable ahorro de espacio, al permitir esta tipología tanto los cruces como los adelantamientos entre ciclistas con una sección típica de tan solo 2,5 metros (Sanz, 1996).

Una característica omnipresente de la red es su segregación total del tráfico rodado, que se consideró necesaria habida cuenta de que el objetivo de la misma no era sólo ofrecer mayor seguridad a los ciclistas actuales, sino también y fundamentalmente atraer a los ciclistas potenciales. Se consideró que estos ciclistas potenciales solo se animarían a usar la bicicleta si percibían un plus de seguridad que sólo la segregación total podría ofrecerles. Esta segregación se consiguió de dos maneras:

- En aquella parte del viario en la que han de coexistir calzada, banda de aparcamientos (o carril-bus) y acerado, se optó de manera casi exclusiva por elevar la vía ciclista a la altura

${ }^{9}$ En Ayuntamiento de Sevilla (2006-B) se citan una media 169 equipamientos (entre deportivos, educativos parques y servicios de interés público o social) relacionados con cada uno de los itinerarios de la red principal de carriles-bici. 
del acerado, diferenciándola de éste mediante el tipo y el color del pavimento de acuerdo con la normativa vigente en Andalucía (Decreto 293/2009, de 7 de julio, BOJA 21 de julio de 2009) y adoptando preferentemente la tipología de "pista bici" separada de la zona peatonal por el arbolado (Sanz, 1996, p. 60) para lo que se aprovechó el arbolado preexistente (Ver Figuras 8 y 9). De este modo se permite el acceso fácil de los vecinos (especialmente los discapacitados) a los vehículos aparcados y no se introducen bordillos ni otros obstáculos adicionales en la acera (A Contramano, 2011-B), al mismo tiempo que se diferencia claramente (mediante la textura y color del pavimento) la zona dedicada al tráfico ciclista de la zona dedicada a los peatones.

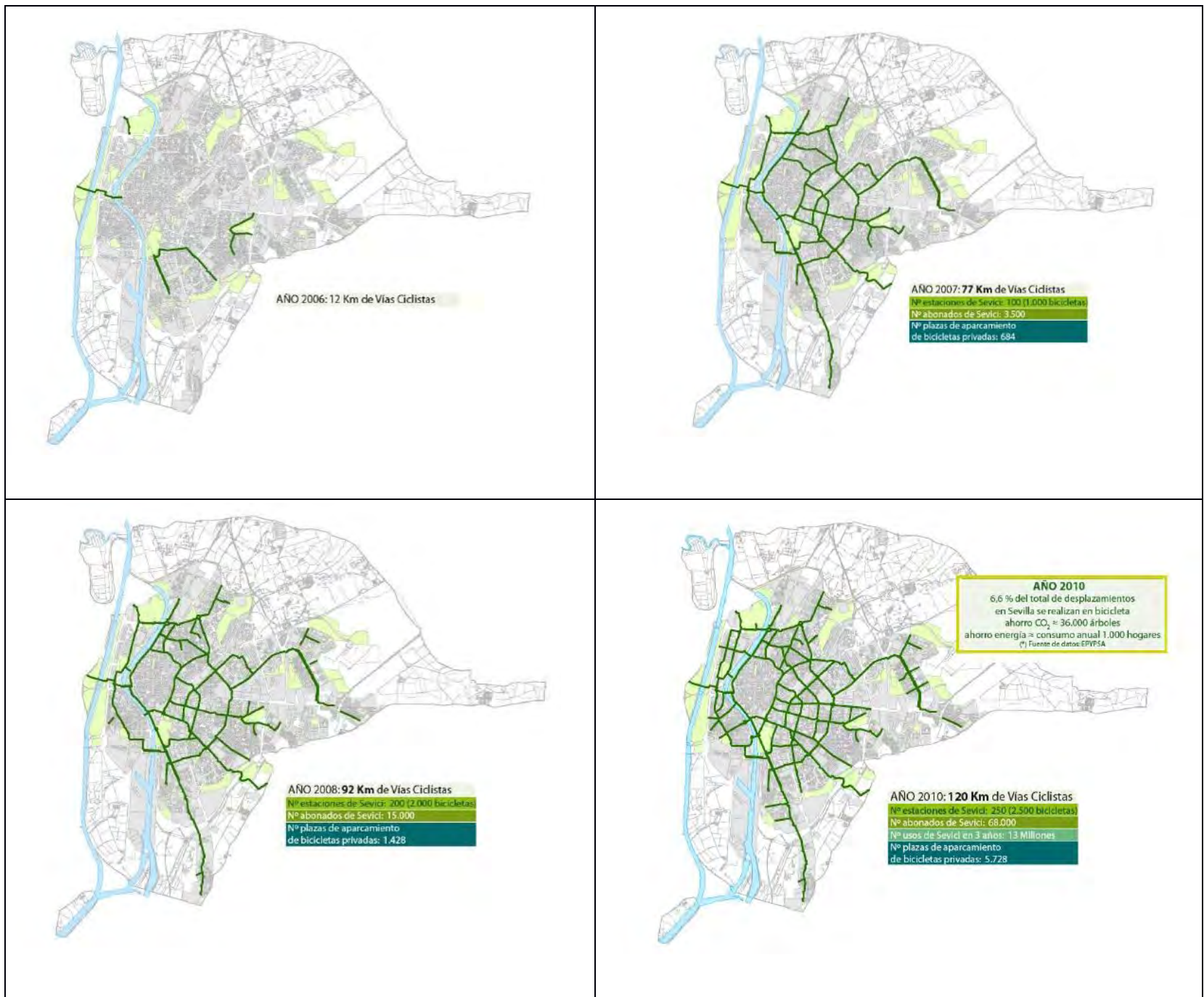

Figura 7. Evolución de la red de vías ciclistas de Sevilla. Fuente: Oficina de la Bicicleta <http://www.sevilla.org/sevillaenbici/>.

- En aquella parte del viario carente de banda de aparcamiento, se optó bien por el modelo anterior, bien por un modelo de carril-bici protegido al nivel de la calzada ${ }^{10}$, separado físicamente de ésta por algún elemento, generalmente discontinuo para favorecer las labores de limpieza (Ver Figuras 8 y 10).

\footnotetext{
${ }^{10}$ Esta última configuración presenta, en opinión del autor, múltiples ventajas de coste y seguridad.
} 

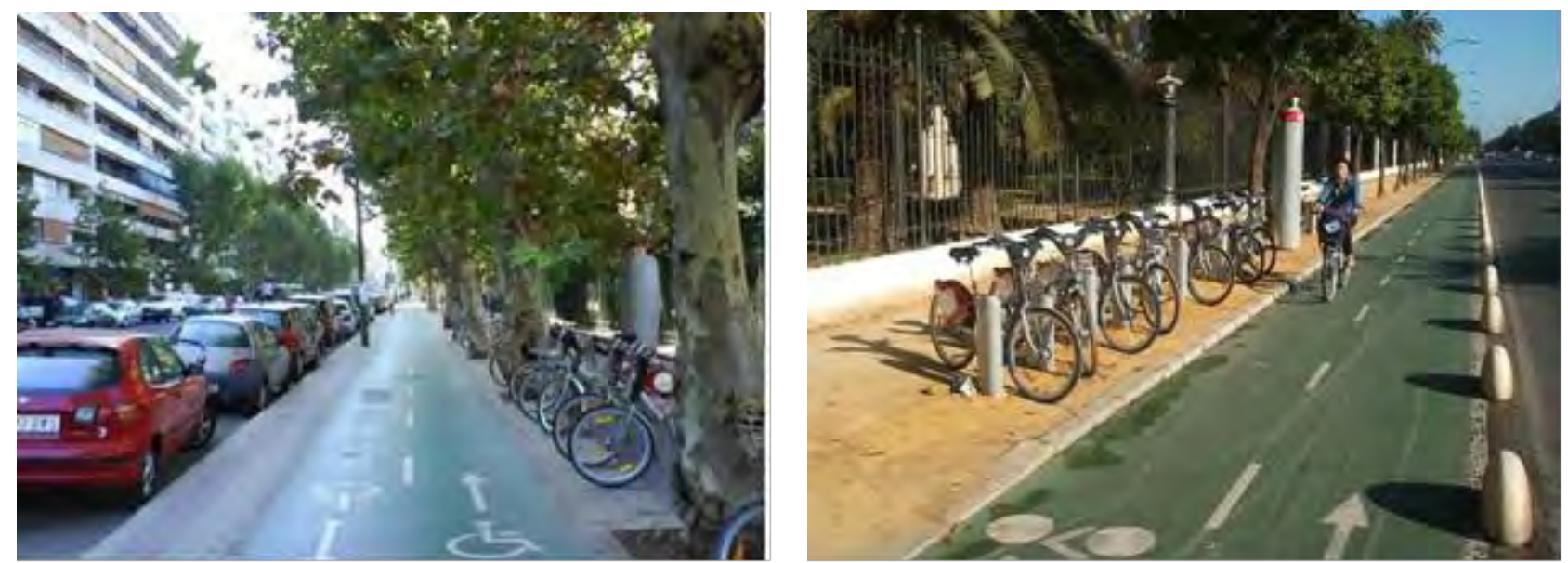

Figura 8. Vías ciclistas en la Av. de Reina Mercedes y en el Paseo de las Delicias (Sevilla).
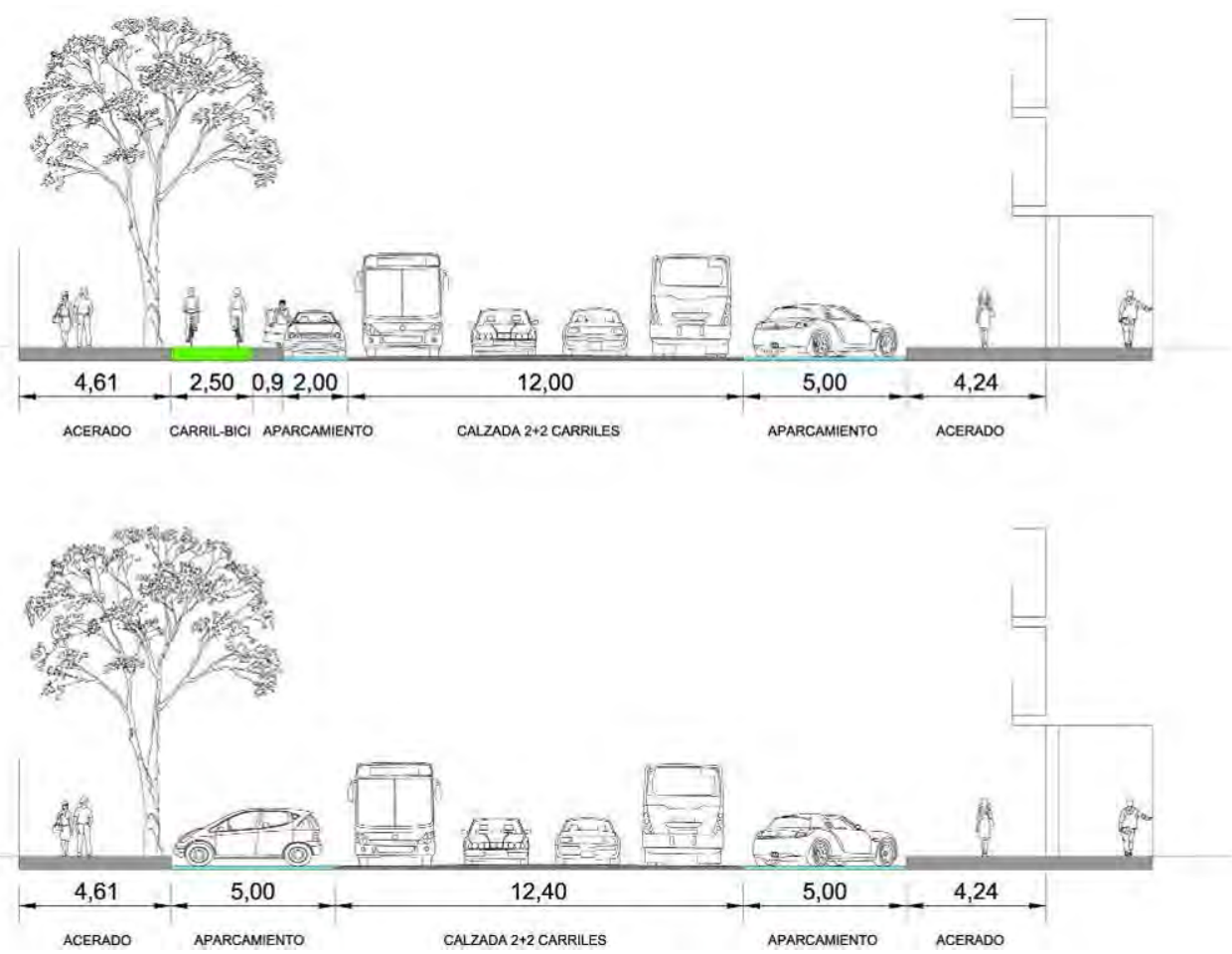

Figura 9 Secciones del viario en la Av. de Reina Mercedes. Actual (arriba) y anterior a la creación de la vía ciclista (abajo).

Las intersecciones se resolvieron casi siempre acompasando el paso de los ciclistas al de los peatones, como corresponde a un diseño de pista-bici segregada del tráfico rodado (Sanz, 1996, p.73), mientras que la integración con las paradas de autobuses se resolvió, como norma general, haciendo pasar la vía ciclista por detrás de éstas (Sanz, 1996, p.66, ilustración).
En cuanto al color y pavimento uniforme a lo largo de toda la red, aunque pueda parecer una cuestión menor, reviste especial importancia a la hora de dotarla de visibilidad para el usuario, que en buena parte debido a estas características llega a percibirla como una infraestructura única capaz de llevarle, a lomos de su bicicleta, de cualquier punto a cualquier otro punto de la ciudad. 

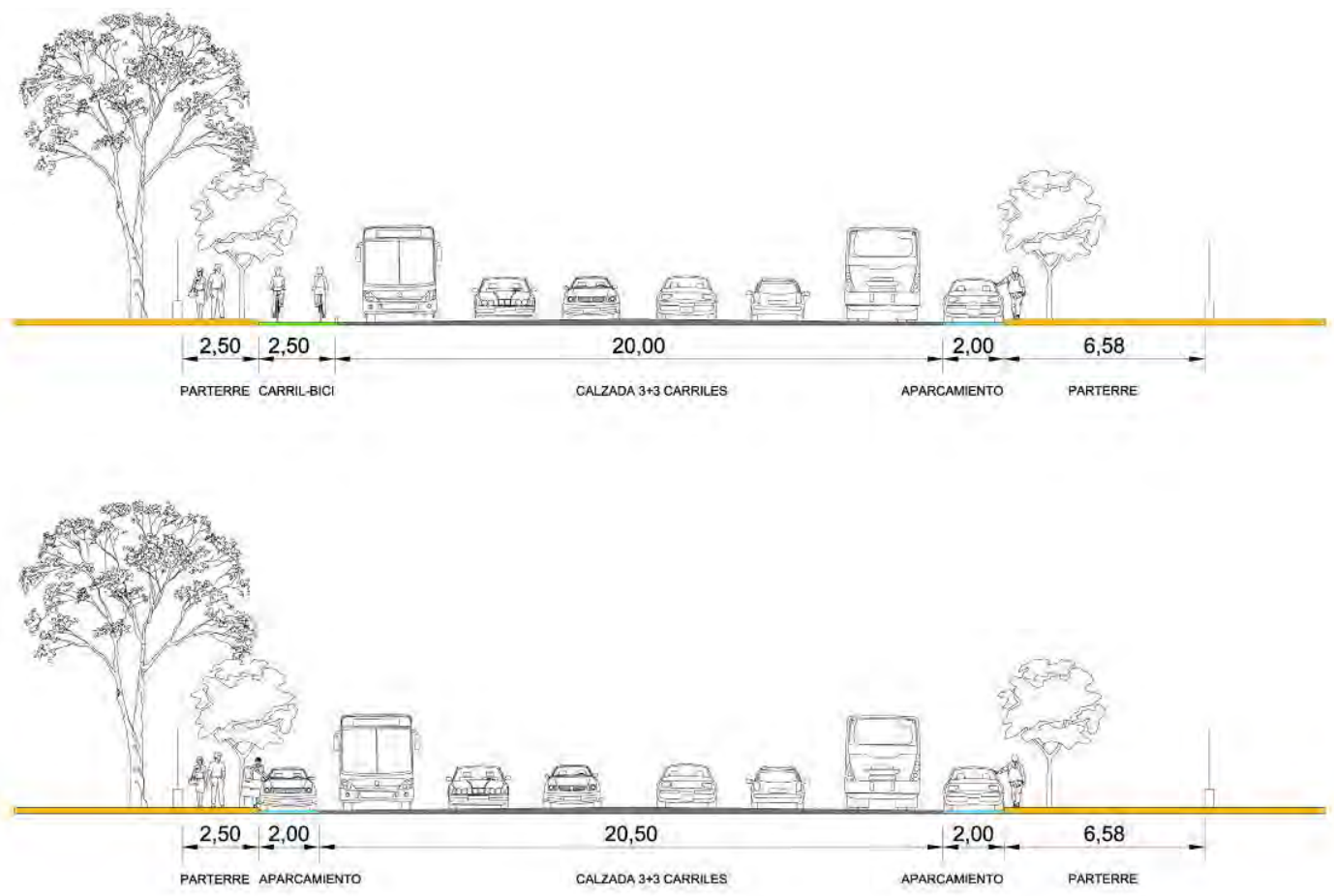

Figura 10 Secciones del viario en el Paseo de las Delicias. Actual (arriba) y anterior a la creación de la vía ciclista (abajo).
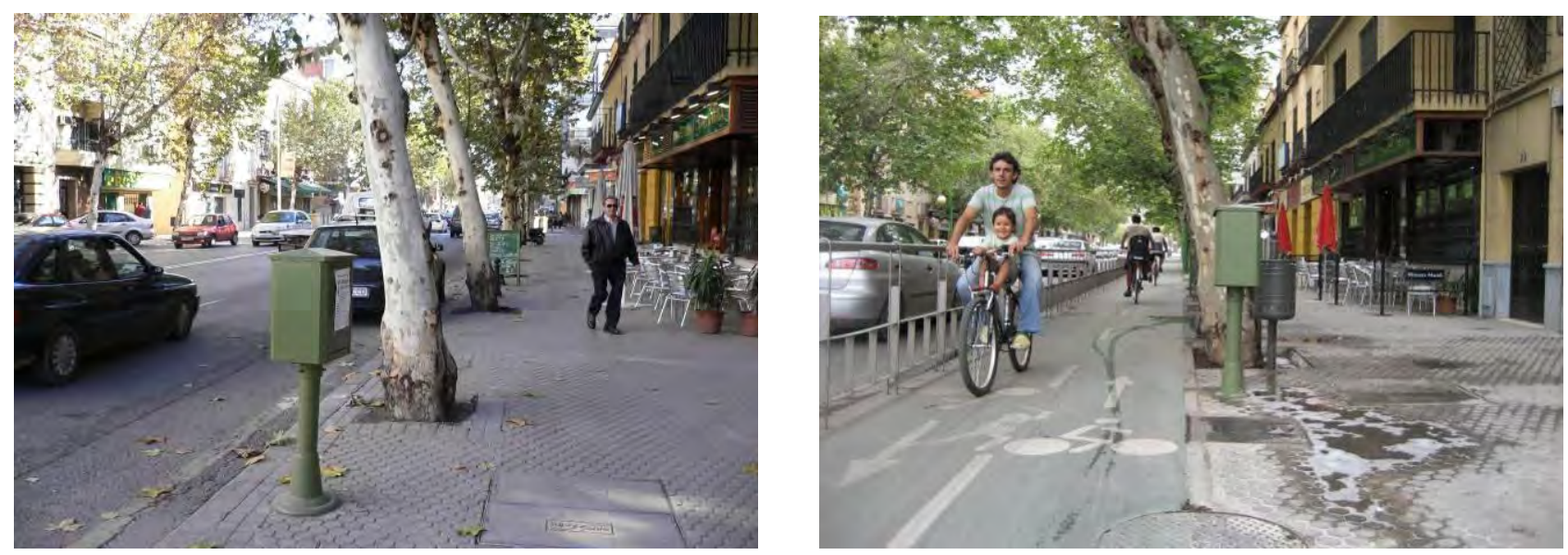

Figura 11. Imágenes de la Ronda Histórica (C/ Resolana) antes y después de la creación de la vía ciclista.

La creación de una nueva infraestructura en la ciudad consolidada implica forzosamente la ocupación un espacio previamente dedicado a otros usos. Tiene pues sentido preguntarse acerca de los usos previos del espacio público sobre el que se construyó mayoritariamente la infraestructura ciclista. $Y$, tratándose de viario, la pregunta específica es si este uso previo era acera, carril de circulación o banda de aparcamiento. Los criterios constructivos ya mencionados prefiguran soluciones constructivas en las que la vía ciclista se hace ocupando espacio antes ocupado por el automóvil privado, fundamentalmente bandas de aparcamiento (ver Figuras 8-11). En concreto, cuando la vía ciclista discurre a nivel del acerado, el uso del arbolado pre-existente como separación entre la vía ciclista y la zona peatonal, implica una reurbanización de la acera, ampliándola para dar cabida a una vía ciclista entre la línea de árboles y la calzada (ver ejemplos en Figuras 9 y 11). En el caso de la Ronda Histórica en su tramo más congestionado, entre la Puerta de la Carne y La Barqueta, un reciente Estudio (A Contramano, 2008) ha demostrado que el $88 \%$ de las vías 
ciclistas se realizaron sobre calzada o banda de aparcamiento, siguiendo el modelo descrito más arriba y que se ejemplifica en la Figura 11. Desgraciadamente, no se dispone, a este respecto, de un estudio cuantitativo similar que abarque la totalidad de la red. No obstante, la conclusión general que se deduce del análisis de los proyectos de obra correspondientes a la red básica de vías ciclistas (Gerencia de Urbanismo, 2006-11) es que, como regla general, estas vías se realizaron sobre bandas de aparcamiento pre-existente, o reduciendo el ancho de los carriles de circulación, o ambas cosas a la vez. Evidentemente hay excepciones a esta regla general, en unos casos (p. ej. a lo largo de la Calle Torneo) justificadas por el ancho más que suficiente del acerado, pero en otros (p. ej., en la Av. de Carlos V) mucho más difíciles de justificar y que exigen una reforma urgente $^{11}$.

Finalmente, es preciso indicar como se solucionó la movilidad ciclista por el Casco Histórico de la ciudad. Como se puede apreciar en la Figura 7 no se habilitaron vías ciclistas en dicho recinto. Por razones evidentes de espacio y porque, en ese entorno, se confía la seguridad del tráfico ciclista a las medidas de pacificación del tráfico y de peatonalización que se fueron poniendo en práctica de forma simultánea a la implantación de la red de vías ciclistas. Aun así, el Casco Histórico es una de las zonas de la ciudad con mayor densidad de tráfico ciclista, lo que unido a su progresiva peatonalización, ha generado tensiones que se han tratado de resolver mediante la aplicación de la Ordenanza de Circulación de Peatones y Ciclistas, que se analizará a continuación.

\footnotetext{
${ }^{11}$ Aunque solo sea porque se incumplen las normas generales de dejar un paso mínimo peatonal de 1,5 metros en toda la calle, y de no hacer la vía ciclista adosada a la línea de fachadas. (Decreto 293/2009 - BOJA 21 de julio de 2009).
}

\section{La Ordenanza de Circulación de Peatones y Ciclistas}

Concebida originariamente como un instrumento para ordenar el tráfico por las nuevas vías ciclistas, la Ordenanza ${ }^{12}$ fue ampliando paulatinamente su ámbito de aplicación para dar cobertura tanto al proyecto de restricciones al tráfico de automóviles de no residentes en el Casco Histórico (conocido como "Plan Centro"), como a la implantación del tranvía en la zona mas céntrica de la ciudad. Como consecuencia, la regulación del tráfico ciclista queda reducida a un título de dicha Ordenanza (Título III) con un total de 11 artículos.

Estos 11 artículos desarrollan un modelo muy similar al vigente en otras ciudades españolas con cierta presencia de la bicicleta en su sistema de movilidad. En lo esencial, se siguió el modelo de Barcelona, siendo principales rasgos de la reglamentación los siguientes:

- Las vías ciclistas son de uso exclusivo para ciclistas, patinadores y sillas de discapacitados.

- Obligatoriedad de circular por las vías ciclistas allí donde existan ${ }^{13} \mathrm{y}$, en caso contrario, por la calzada ordinaria (con las excepciones que se verán).

- Obligatoriedad de llevar timbre y luces en la bicicleta.

- Posibilidad de crear itinerarios para ciclistas en zonas peatonales, donde los ciclistas habrán de circular a velocidad moderada y respetando la prioridad de los peatones.

- Posibilidad de circular por aceras y zonas peatonales de más de 5 metros de ancho a velocidad moderada $(10 \mathrm{~km} / \mathrm{h})$ y respetando la prioridad de los peatones, siempre que no

\footnotetext{
${ }^{12}$ Publicada en el BOP de Sevilla no. 117 de 22 de mayo de 2008 y posteriormente modificada (BOP no. 229 de 2 de octubre de 2010).

${ }^{13}$ Esta obligatoriedad ha sido contestada por las asociaciones de usuarios de la bicicleta, por considerar que las vías ciclistas deben ofrecer una alternativa segura al tráfico ciclista sin constreñirlo.
} 
exista vía ciclista específica. El Ayuntamiento podrá establecer la prohibición de circular en bicicleta, siempre o a determinadas horas, en determinadas zonas peatonales (de hecho así ha sido en la almendra central del Casco Histórico)

- Posibilidad de establecer calles con circulación a contra-sentido de las bicicletas.

- Las bicicletas deberán ser aparcadas en las parrillas específicas instaladas por el
Ayuntamiento. Caso de no ser esto posible, podrán amarrarse al mobiliario urbano (señales de tráfico, farolas....) o a árboles, sin dañarlos ni alterar su función.

- Se autoriza el transporte de menores (así como de bultos en general) en sillas o remolques homologados.

- Se crea un registro voluntario de bicicletas, gestionado por el Ayuntamiento, cuyo objetivo es la lucha contra el robo.
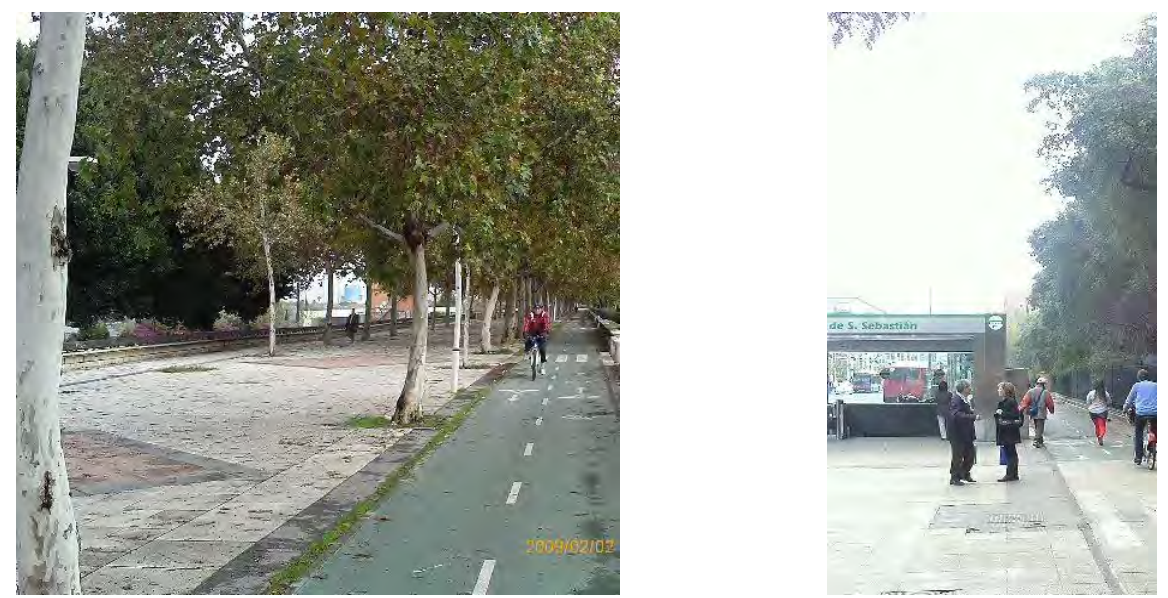

Figura 12. Vías ciclistas en C/Torneo (izda.) y en la Av. de Carlos V (dcha.) En el primer caso puede observarse como el ancho de la zona peatonal y el arbolado en alameda permiten la inclusión de una pista-bici según los criterios ya señalados, sin merma de seguridad para los peatones. En el segundo caso puede verse como la combinación de una acera-bici "a sangre" con la línea de fachada y unas bocas de metro sobredimensionadas, crean situaciones de conflicto bici-peatón.

Es, como puede verse, una reglamentación bastante favorable al ciclista, al que se le dota de un amplio grado de libertad en sus movimientos por la trama urbana. La bicicleta se contempla como una "vehículo sin motor", lo que la coloca (junto a otros vehículos no motorizados) en una categoría aparte y diferenciada tanto de los vehículos a motor como de los peatones. De ese modo se justifica tanto la necesidad de reservar un espacio específico para la bicicleta en la calzada (vía ciclista), como el carácter muchas veces excepcional de la reglamentación del tráfico ciclista (por comparación con el tráfico motorizado) y la posibilidad de convivencia entre la bicicleta y el peatón. La posibilidad de circular de bicicleta por algunas aceras (con un ancho mínimo de 5 metros) hay que entenderla como algo excepcional y, sobre todo, transitorio, en tanto en cuanto no exista ninguna vía ciclista específica (Art. 41). La convivencia de bicicletas y peatones en calles y zonas peatonales habría que abordarla, sin embargo, con una filosofía diferente, en la medida en que esta modalidad podría llegar a ser la predominante en las grandes áreas peatonales de nueva creación, que deberían ser también permeables para las bicicletas y otros vehículos no motorizados. La Ordenanza no diferencia, sin embargo, entre ambos casos, algo que sin duda habrá que corregir en el futuro.

La Ordenanza ha sido una de las actuaciones municipales más polémicas, no sólo por su regulación del tráfico ciclista, sino sobre todo por las 
restricciones impuestas al tráfico de automóviles privados de no residentes en el Casco Histórico de la ciudad. Concretamente, ha sido objeto de una serie de recursos por parte de empresas gestoras de parkings rotatorios en el interior del Casco Histórico, colectivos vecinales y de comerciantes, y ciudadanos particulares. La mayoría de los recursos -una docena aproximadamenteincidieron, en lo que a la bicicleta se refiere, sobre la posibilidad de circular por zonas peatonales y sobre la posibilidad de amarrar las bicicletas a árboles y elementos del mobiliario urbano (farolas, señales...), aspectos en los que el Tribunal Superior de Justicia de Andalucía dio la razón a los demandantes. No obstante, en fecha reciente, el Tribunal Supremo ha considerado el recurso de casación interpuesto por el Ayuntamiento de Sevilla con el apoyo de las asociaciones ciclistas de la ciudad. $Y$ en una sentencia que ha sido calificada de "histórica" ha dictaminado la plena legalidad del texto de la Ordenanza, que se mantiene pues en vigor.

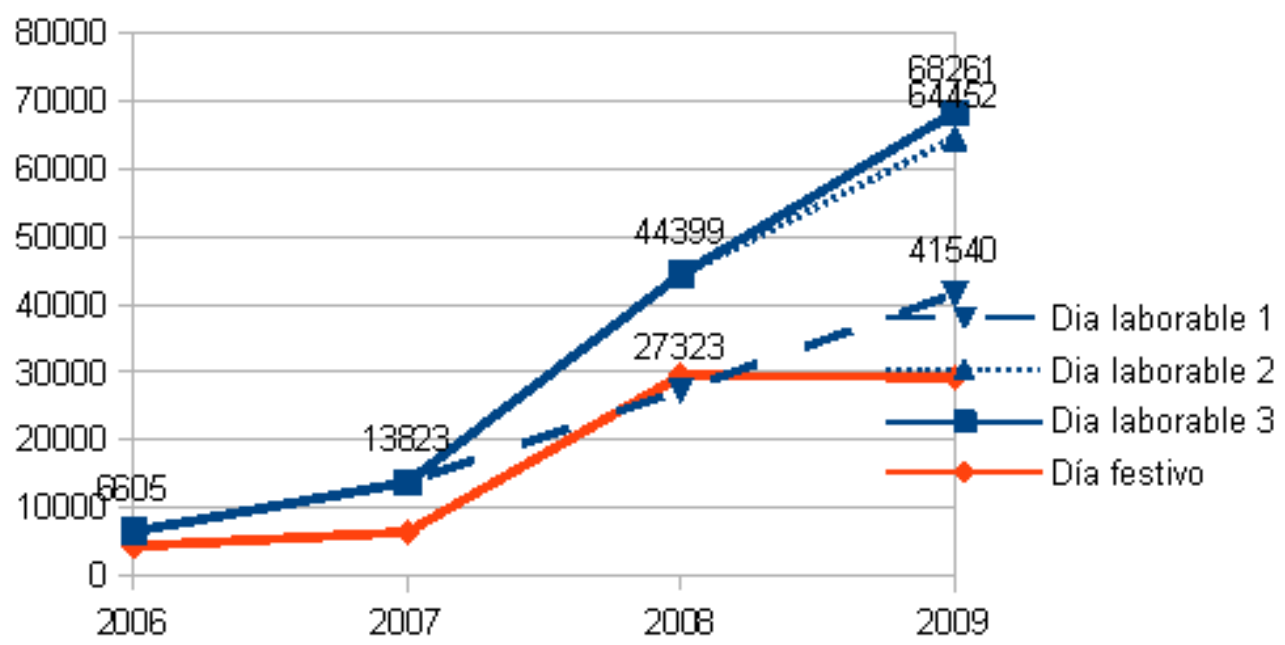

Figura 13. Resultados de los conteos de ciclistas (Ayuntamiento de Sevilla, 2006-2010). Las líneas discontinuas indican los resultados cuando sólo se contabilizan los resultados de los puntos de aforo del conteo inmediatamente anterior.

\section{La evolución de la movilidad ciclista en el núcleo urbano de Sevilla}

La principal herramienta de la que disponemos a la hora de evaluar la movilidad ciclista en el núcleo urbano de Sevilla son las sucesivas encuestas y conteos que han venido realizándose en la ciudad. Los trabajos de campo se realizaron durante los meses de septiembre de $2006^{14}$, julio de 2007, mayo de 2008 y noviembre de 2009 (Ayuntamiento de Sevilla, 2006-2010). Los conteos evidencian un crecimiento acelerado en el número de usuarios de las vías ciclistas, que en

\footnotetext{
14 Este conteo de realizó justo al incio de las obras, a fin de disponer de una estimación del tráfico ciclista antes de la implantación de la red.
}

el periodo estudiado se multiplicaron por un factor del orden de 10 [sic].

Del análisis de los gráficos de la Figura 13 se desprende que la bicicleta es usada en Sevilla principalmente para los desplazamientos cotidianos, de ahí que el uso de las vías ciclistas sea siempre sensiblemente superior en día laborable que en día festivo. También es significativo el reparto de género, que ha ido evolucionando desde un predominio de los varones hacia un reparto bastante equilibrado en el ultimo conteo (ver Figura 12), lo que sin duda es un dato positivo que muestra como la creación de la infraestructura ciclista ha contribuido a ofrecer una sensación de seguridad entre las usuarias potencia- 
les que antes no percibían.

En cuanto a la distribución por edades, predomina el tramo de edad entre 18 y 30 años (Ayuntamiento de Sevilla, 2010), aunque la distribución vuelve a subir para el tramo entre 46 y 65 años, lo que sin duda expresa un mayor uso del coche entre el sector "dominante" de la población (varones de 30 a 45 años). Esta particularidad está sin duda en el origen de las diferentes valoraciones de la infraestructura ciclista por los diferentes sectores de la población y contribuye a su desigual reflejo por los medios de comunicación, que tienden a reflejar las opiniones de dicho sector "dominante". Finalmente, el principal motivo de los desplazamientos en día laborable es por trabajo y gestiones relacionadas con el trabajo (34\%) seguido muy de cerca por los estudios (32\%), lo que muestra que la bicicleta ha irrumpido con fuerza como un modo de transporte cotidiano más, capaz de vehicular la movilidad obligada de los sevillanos y las sevillanas.

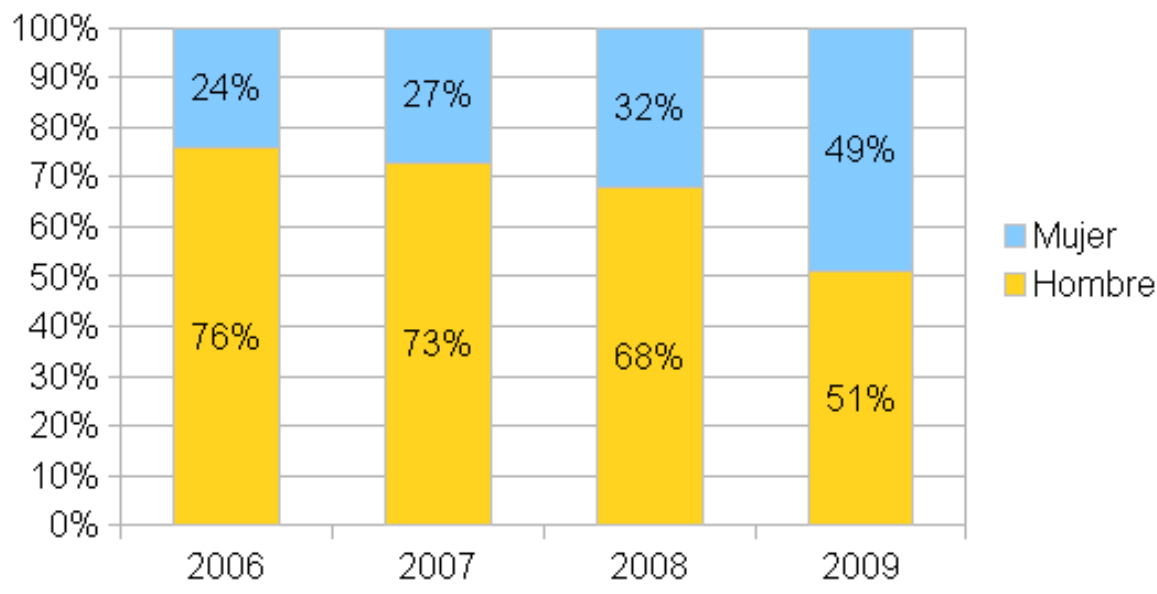

Figura 14. Evolución del reparto de género entre hombres y mujeres (Ayuntamiento de Sevilla, 2006-2010).

En cuanto al modo de procedencia de los nuevos usuarios de la bicicleta, los resultados de la encuesta de 2009 (Ayuntamiento de Sevilla, 2010) muestran que un $37 \%$ provienen del autobús urbano, el $32 \%$ del coche, el $26 \%$ del modo andando y el $5 \%$ de la motocicleta. Estos datos indican un impacto bastante ponderado de la bicicleta entre los diferentes modos de transporte, con predominio de los desplazamientos motorizados privados (coche y moto) y de los desplazamientos en transporte público, con un $37 \%$ cada uno. Estamos pues ante un fenómeno de calado, que implica un cambio profundo en los hábitos de movilidad de los sevillanos y las sevillanas, con consecuencias en el reparto modal motorizado / no motorizado y no, como algunas veces se ha dicho de otras experiencias de promoción del ciclismo urbano, ante un simple trasvase de viajes andando hacia la bicicleta.

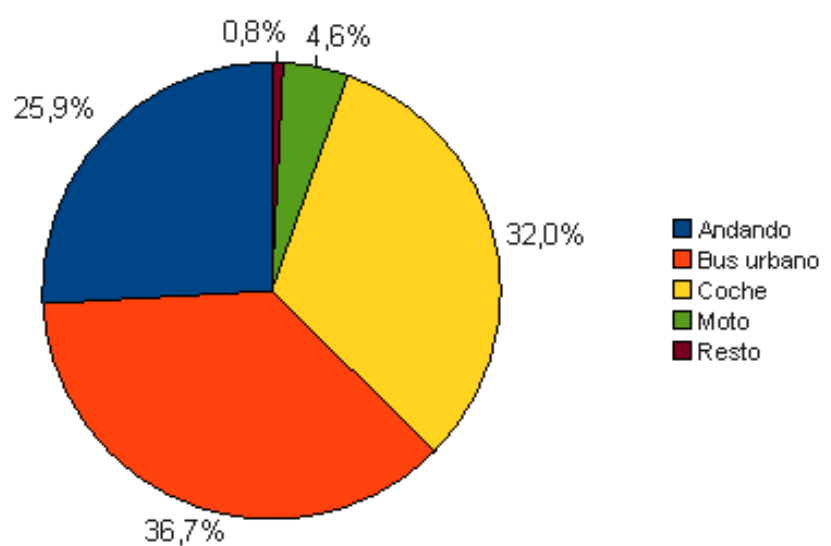

Figura 15. Procedencia de los nuevos usuarios de la bicicleta (Ayuntamiento de Sevilla, 2010).

En cuanto a la participación de la bicicleta en el reparto modal ${ }^{15}$ de los desplazamientos internos

\footnotetext{
${ }^{15}$ Salvo que se especifique lo contrario, por "reparto modal" entendemos los porcentaje sobre los desplazamientos totales, incluyendo desplazamientos a pie, de la ciudad.
} 
de Sevilla, ésta no puede deducirse directamente de los resultados de los conteos de la Figura 14, ni de las encuestas, aunque ambos nos dan pistas interesantes al respecto. Los conteos, concretamente, no contabilizan desplazamientos sino pasos por determinados puntos de aforo que, dada su densidad, pueden contabilizar varias veces un mismo desplazamiento. Por otro lado solo contabilizan los desplazamientos que usan las vías ciclistas, por lo que los demás desplazamientos -por ejemplo los desplazamientos interiores al Casco Histórico- no son contabiliza$\operatorname{dos}^{16}$. Las encuestas, por su parte, nos ayudan a comprender el impacto de la creciente movilidad ciclista en la participación de otros modos en el reparto modal. No obstante, los cambios en la estructura de la movilidad consecuencia de otras medidas contemporáneas de la implantación de las vías ciclistas, como la implantación del metro o las restricciones al tráfico en el Casco Histórico, han debido tener también un gran impacto en el reparto modal que resulta imposible de estimar a partir solamente de los datos disponibles acerca de la movilidad ciclista.

Aun así, a partir del dato de 41.744 desplazamientos en bicicleta en octubre-noviembre de 2007, correspondientes a un 3,2\% del reparto modal (ver Figura 2), que nos ofrecen las encuestas de movilidad (Consorcio de Transportes, 2007), es posible hacer algunas estimaciones. Estas estimaciones se basarán en una simple regla de tres, en la que se asumirá que el incremento modal correspondiente a la bicicleta es simplemente proporcional al incremento de uso contabilizado en los sucesivos conteos de la Figura 14. Los conteos más cercanos a noviembre de 2007 de que disponemos corresponden a

16 Sólo en el conteo de octubre - noviembre de 2009 se incluyó un punto de conteo en el interior del Casco Histórico, en la Avenida de la Constitución, donde se obtuvo precisamente uno de los mayores aforos: 3.809 ciclistas en día laborable. julio de 2007 (Ayuntamiento de Sevilla) y a mayo de 2008 (Ayuntamiento de Sevilla), es decir 4 meses antes y 6 meses después de la realización de la encuesta, respectivamente. Como los datos de la encuesta de movilidad son de noviembre de 2007, asumiendo una variación lineal entre ambos conteos obtenemos la fórmula $\mathrm{N}=\mathrm{N} 07 \cdot 0,6+$ N08·0,4 para el número estimado de un hipotético aforo en noviembre de 2007 , en función de los aforos en julio de 2007, N07, y en mayo de 2008, N08. No obstante, esta estimación presenta algunos inconvenientes serios. En primer lugar no tiene en cuenta la variación estacional de los viajes en bicicleta, que cabe presumir sea significativa entre julio (mes en el que el periodo lectivo ha finalizado para la mayoría de los estudiantes) y mayo $^{17}$. Tampoco tiene en cuenta que los puntos de aforo en ambos conteos fueron diferentes (el número de puntos se incrementó notablemente en 2008 respecto de 2007), por lo que existe una gran incertidumbre acerca de cual de los datos correspondientes a 2008 escoger (ver Figura 14). Otra posibilidad es suponer una variación lineal entre mayo de 2008 y noviembre de 2009 y extrapolar a noviembre de 2007. Aunque las fechas aquí están más alejadas, esta metodología tiene las ventajas de que no cabe esperar una gran variación estacional entre mayo y noviembre ${ }^{18} \mathrm{y}$ de que los puntos de aforo fueron los mismos en ambos conteos, con la única excepción del ya mencionado punto de conteo en la Avenida de la Constitución en el año 2009. Esta metodología da la expresión $\mathrm{N}=(\mathrm{N} 08 \cdot 3-\mathrm{N} 09) / 2=34.373$, que sería el valor obtenido en un hipotético conteo en noviembre de 2007. Usando este valor y mediante una simple regla de tres se obtienen los siguientes valores de reparto modal para la bicicleta:

\footnotetext{
17 De hecho, los datos disponibles de conteos continuados en algunos puntos aislados muestran una gran variación estacional entre julio y mayo.

${ }^{18}$ De nuevo así lo demuestran los conteos continuados en puntos aislados.
} 


\begin{tabular}{|c|c|c|}
\hline & Noviembre 2007 & Noviembre 2009 \\
\hline No. de desplazamientos $^{\circ}$ & 41.744 & 78.273 \\
\hline Porcentaje modal & $3,2 \%$ & $6,0 \%$ \\
\hline
\end{tabular}

Tabla 1. Estimación de la participación de la bicicleta en el reparto modal del núcleo urbano de Sevilla.

El porcentaje obtenido para noviembre de 2007 difiere ligeramente del estimado en (Ayuntamiento de Sevilla, 2010) $(6,6 \%$ de la movilidad mecanizada, que correspondería al $5 \%$ de la movilidad global), básicamente porque aquél trabajo hace corresponder directamente los resultados del conteo de mayo de 2008 con los desplazamientos contabilizados en la encuesta de noviembre de 2007, hipótesis en mi opinión inaceptable. Hay que decir también que en el VIII Barómetro Socioeconómico de Sevilla (Centro Andaluz de Prospectiva, 2011), correspondiente a mayo de 2009 , un $4,1 \%$ de los encuestados citaban a la bicicleta como su medio habitual de transporte, un dato que casaría bastante bien con los resultados anteriores si se considera que la bicicleta (sobre todo la bicicleta pública) se ha convertido en un importante modo de transporte ocasional para los vecinos de Sevilla. Es significativo a este respecto el dato proporcionado por el Barómetro de diciembre de 2010 , según el cual un $14,5 \%$ de los sevillanos manifestaban usar (habitual $u$ ocasionalmente) Sevici, y un $32,1 \%$ las vías ciclistas, lo que viene a demostrar hasta que punto la bicicleta ha calado como opción de transporte en la ciudad.

Así pues podemos afirmar con casi total seguridad que la participación de la bicicleta en el reparto modal de los desplazamientos interiores de Sevilla oscilaba, en noviembre de 2009 , en una horquilla entre el $5 \%$ y el $6 \%$. Estos porcentajes se corresponderían con un número de usuarios habituales del orden del $4 \%$ del total de la población. $Y$ con altos porcentajes de uso ocasional tanto de la bicicleta en general (en torno al 30\%) como de la bicicleta pública en particular (en torno al $14 \%$ ). Estas cifras eran, en su momento, las más altas de toda España y muy probablemente se hayan incrementado todavía más en la actualidad, aunque sería demasiado arriesgado aventurar estimaciones concretas.

\section{La percepción ciudadana}

La realización de una obra lineal de $120 \mathrm{~km}$ de longitud en tan corto periodo de tiempo no puede pasar desapercibida en ninguna ciudad, y menos aún si dicha actuación se justifica con el propósito de introducir un nuevo modo de transporte de escasa tradición en la ciudad. Y, por supuesto, dado que dicha obra ha de realizarse necesariamente en detrimento de alguna otra infraestructura preexistente, ha de generar también cierto rechazo. Como señala Pedro Malpica:

"...casi desde las primeras fases de construcción del carril-bici y la implantación del servicio Sevici, se generó una polémica de ámbito local en oposición a dichas medidas. En ella participaron partidos políticos, candidatos a edil, un buen número de los medios de comunicación con presencia en la ciudad, relevantes articulistas sevillanos, gremios de comerciantes y taxistas, alguna asociación de vecinos de incierta representatividad, empresas relacionadas con el tráfico motorizado (en especial, garajes situados en el centro de la ciudad) y portavoces de los derechos del automovilista. Los argumentos empleados (veraces o no) abarcaban la molestia por las obras, la desaparición de plazas de aparcamiento para automóviles y de espacio peatonal en acerados, los costes económicos, el perjuicio al comercio, la competencia desleal al taxi, el ciclismo urbano como actividad pasada de moda y propia de "pobres", la escasa demanda social que tendrían 
las nuevas instalaciones, la cesión de excesivos privilegios al colectivo ciclista, o la irresponsable conducción de los usuarios de bicicletas y las molestias que generan al resto de la población... " (Malpica 2010).

El uso masivo de dicha nueva infraestructura por la población ${ }^{19}$ y la incontestable rentabilidad de la inversión económica ${ }^{20}$ han sido la contestación más eficaz a dichas críticas, en lo que cabe calificar como uno de los mas meridianos ejemplos del abismo que a veces separa la opinión pública de la opinión publicada.

Así, en la Tabla 2, pueden verse los porcentajes de aceptación y la valoración (en una escala de 0 a 10) tanto de las vías ciclistas de Sevilla (carrilbici), como del servicio de bicicletas públicas (Sevici) reflejados en los sucesivos Barómetros Socioeconómicos de Sevilla (Centro Andaluz de Prospectiva, 2007-2011). Como puede observarse, la creación de las vías ciclistas contó desde el principio con un alto grado de aprobación por parte de la población de Sevilla. Asimismo, el servicio municipal de bicicletas públicas ha obtenido también de forma sistemática una valoración bastante alta, aunque con altibajos que correspondieron a problemas puntuales de vandalismo.

Como puntos más débiles de las actuaciones acometidas cabe destacar un cierto nivel de desacuerdo con los trazados de las vías ciclistas correspondientes a la segunda fase de las obras, que solo alcanzan un $51,7 \%$ de acuerdo en el Barómetro de diciembre de 2009 y, sobre todo, la posibilidad de que los ciclistas circulen por las aceras y zonas peatonales contemplada en la Ordenanza, que sólo alcanza un $37 \%$ de acuerdo en el Barómetro de diciembre de 2010.

\footnotetext{
19 Hasta el punto de que una de las quejas mas reiteradas de los operarios durante la realización de las obras fue que los ciclistas quitaban las vallas e invadían las vías ciclistas antes de que éstas estuviesen finalizadas (MALPICA, 2010).

Para convencerse de ello basta con comparar la inversión en vías ciclistas, de 32 millones de euros, con la inversión contemporánea en el Metro, de aproximadamente 600 millones de euros, para un número de usos aproximado en día laborable de 70.000 y 30.000 , respectivamente.
}

Respecto del descenso en el acuerdo con el carril-bici debido a los nuevos trazados hay que decir que, en el momento de realizarse la encuesta, las obras estaban aproximadamente en su ecuador, lo que sin duda influyó en el resultado, debido a las inevitables molestias causadas por éstas, recuperándose en sucesivas encuestas la valoración del carril-bici. Respecto al dato correspondiente a la posibilidad de que los ciclistas circulen por determinadas aceras y zonas peatonales, hay que decir que la encuesta se realiza en un momento de gran debate sobre este tema, a consecuencia de las sucesivas sentencias judiciales, primero en contra y luego a favor de la Ordenanza, y con una fuerte campaña en la prensa escrita de la ciudad. Así, la propia forma de plantear la pregunta : "¿Considera acertada la decisión de permitir circular a las bicicletas por las zonas peatonales?" es capciosa en la medida en que da a entender que dicha circulación está permitida por cualquier acera o zona peatonal cuando, como ya vimos en la Sección $4^{a}$, esta posibilidad se contempla en la Ordenanza de forma bastante excepcional y siempre sujeta a restricciones. En cualquier caso, es evidente que este es uno de los puntos débiles (quizás el único realmente) en lo que respecta a la aceptación ciudadana de la política municipal de promoción del ciclismo urbano, por lo que se hace necesaria una reflexión en profundidad al respecto. De hecho y teniendo en cuenta de que en la actualidad muy pocas aceras de la ciudad cumplen los requisitos mínimos necesarios (más de 5 metros de anchura e inexistencia de vía ciclista en las proximidades) para la circulación de los ciclistas, quizás haya llegado el momento de plantearse una modificación de la norma -que tuvo siempre una vocación de provisionalidad- en lo que a la circulación de bicicletas por las aceras se refiere. Otra cosa sería, como ya mencionamos en la Sección $4^{\mathrm{a}}$, la circulación por 
las cada vez más numerosas calles y zonas peatonales de la ciudad, que requeriría probablemente un tratamiento específico si queremos mantener su permeabilidad para las bicicletas.

\begin{tabular}{|c|c|c|c|c|c|c|c|}
\hline & Dic. 2007 & Junio 2008 & Dic. 2008 & May. 2009 & Dic. 2009 & Junio 2010 & Dic. 2010 \\
\hline Sevici & & & 7,19 & 7,03 & 6,04 & & 6,56 \\
\hline Carril-bici & $71,9 \%$ & & $73,5 \%$ & & $51,7 \%$ & 5,68 & 6,77 \\
\hline
\end{tabular}

Tabla 2. Porcentajes de aceptación y/o valoración (de 0 a 10) de Sevici y de los carriles-bici de Sevilla. Fuente: Barómetros Socioeconómicos de Sevilla, Centro Andaluz de Prospectiva (2007-2011).

De los datos anteriores se desprende que la bicicleta ha calado profundamente en la ciudad, convirtiéndose en una opción más de transporte para amplios sectores de la población, con independencia de su género, edad, clase social o ideología política ${ }^{21}$. Parecería pues que estamos ante un fenómeno irreversible, cuya permanencia en el tiempo -si no su crecimiento progresivoestá asegurada. Sin embargo, como veremos en la próxima sección, este fenómeno no deja de ser metropolitano de Sevilla, lo que sin duda constituye una de sus mayores debilidades. Por otro lado, no debemos olvidar que esta "explosión" del ciclismo urbano en Sevilla ha sido la consecuencia de unas políticas municipales de apoyo muy concretas. No sabemos que ocurriría si dichas políticas cesasen de repente, pues no debemos olvidar que la mayoría de los usuarios de la bicicleta lo hacen por razones de tipo práctico (comodidad, economía, ahorro de tiempo...) (Ayuntamiento de Sevilla, 2010), y no por motivos de conciencia ecológica o similares. Así, bastaría con una cierta dejadez en el mantenimiento de la infraestructura ciclista de la ciudad (vías ciclistas, Sevici y aparcamientos), producto por ejemplo del traspaso de las competencias correspondientes a otra Delegación Municipal (con la eventual desaparición de la Oficina de la Bicicleta), para iniciar

21 Esto se desprende también de los datos de la encuesta realizada a los usuarios de la bicicleta y publicada en Ayuntamiento de Sevilla (2010). una fase de menor comodidad o seguridad en el uso de la bicicleta y, consecuentemente, un descenso en su uso. Similar efecto tendría un endurecimiento de la normativa relativa al tráfico ciclista, restringiendo la permeabilidad del Casco Histórico para las bicicletas o impidiendo el uso del mobiliario urbano para su amarre, por ejemplo. No debemos olvidar que nada es irreversible en un organismo tan vivo y cambiante como la ciudad moderna.

\section{La bicicleta en el contexto metropolitano}

Ya se ha mencionado en repetidas ocasiones a lo largo de este artículo el divorcio existente entre las pautas de movilidad del núcleo central y de la corona metropolitana. La movilidad ciclista no sólo no es una excepción a esta regla, sino que es la más clara expresión de la misma. Las escasas vías ciclistas metropolitanas son inconexas y variopintas, configurando un auténtico catálogo de despropósitos. Así, se dan casos como el del recientemente creado carril-bici de conexión entre Sevilla y La Rinconada, que arranca en una autovía (Figura 16) sin conexión alguna con la red de vías ciclistas de Sevilla, o las precarias conexiones con otras poblaciones cercanas a Sevilla (San Juan de Aznlafarache, La Algaba, Dos Hermanas, Alcalá de Guadaira, Santiponce, etc.) inexistentes o en lamentable estado de conservación. Por no citar las deficiencias crónicas en la 
conservación de la red de vías verdes metropolitana, que obligan a reconstruirlas cada primavera tras el periodo de lluvias. No es pues de extrañar que la movilidad ciclista en la corona metropolitana siga estancada en un raquítico 1\% (Figura 2).

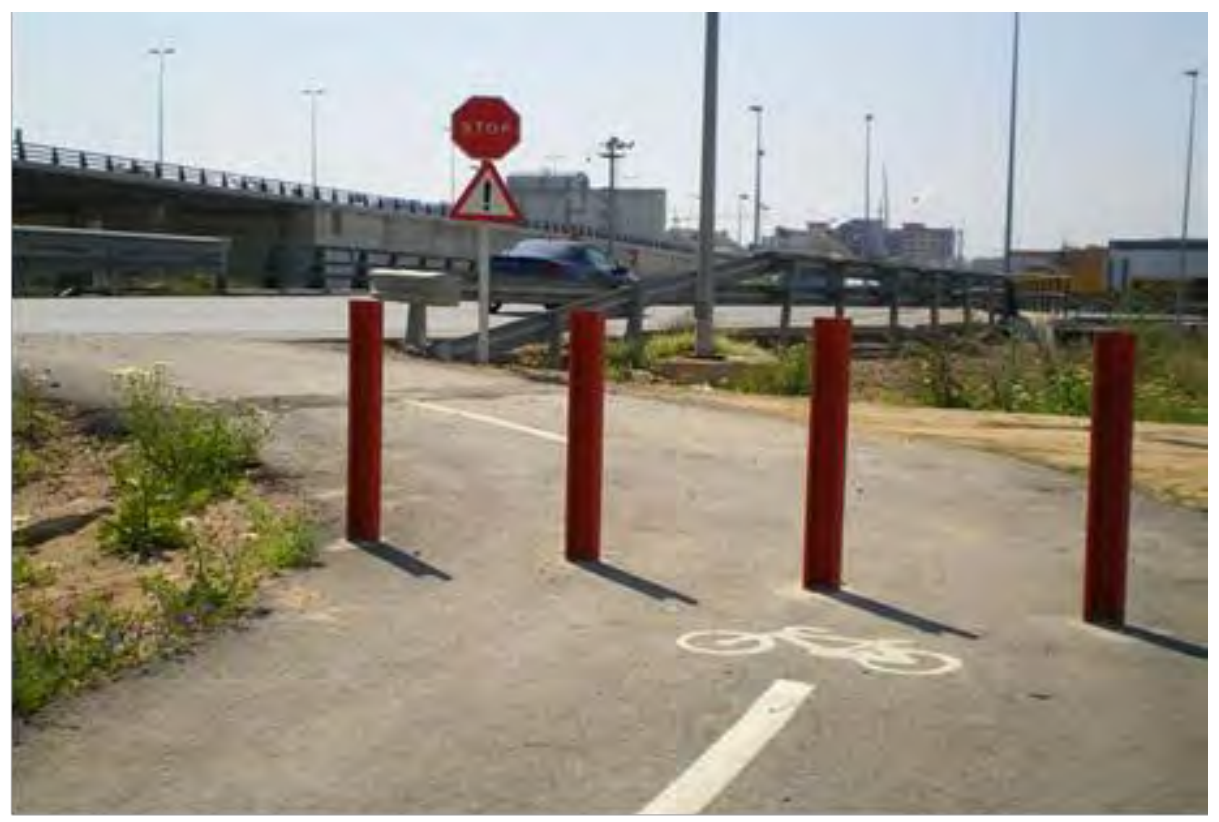

Figura 16. Punto de arranque del carril-bici de conexión con La Rinconada, en la Ronda Súper Norte (Sevilla). Abril de 2009.

Pese a ello, la bicicleta tendría un gran potencial de desarrollo en la corona metropolitana, especialmente en conexión con el transporte público. Ya hemos mencionado el escaso papel jugado por éste en la movilidad de la corona metropolitana, con sólo un $8 \%$ de participación en el reparto modal (Figura 2). Esta magra participación es en parte consecuencia de la propia estructura poblacional de la corona, formada en gran medida por pequeños núcleos de población (antiguos pueblos y nuevas urbanizaciones) dispersos por el territorio. Esta estructura hace casi imposible dotar a la corona de un transporte público eficaz, tanto desde el punto de vista económico como ecológi$\mathrm{Co}^{22}$, debido a la gran cantidad de estaciones necesarias para cubrir el territorio y el elevado número de transbordos. Ahora bien, como pone

\footnotetext{
22 Se calcula que para que un autobús suponga menores emisiones de gases de efecto invernadero que un automóvil ocupado por una persona (la tasa de ocupación de los automóviles es próxima a uno en todas las ciudades españolas), la ocupación media del autobús debe estar en torno a 10 personas.
}

de manifiesto la experiencia de países como Holanda o Dinamarca (Figura 17), entre otros, estas dificultades se superan en cuanto se planifica la movilidad metropolitana en términos de intermodalidad bicicleta-transporte público. Este concepto permite ampliar el radio de acción de las estaciones metropolitanas del transporte público de unos cientos de metros a varios kilómetros, disminuyendo así el número de paradas por un factor del orden de 100 [sic]. Para ello es preciso que se den dos requisitos: una red de vías ciclistas que garantice la accesibilidad de las estaciones del transporte público para la bicicleta y un sistema de aparcamientos o consignas para bicicletas que garanticen el almacenamiento seguro de la bicicleta en la estación por el tiempo que dure el viaje. La existencia en el núcleo central de sistemas de bicicletas públicas, como Sevici o Bus-bici, sin duda complementaría de un modo muy eficaz estas actuaciones. 


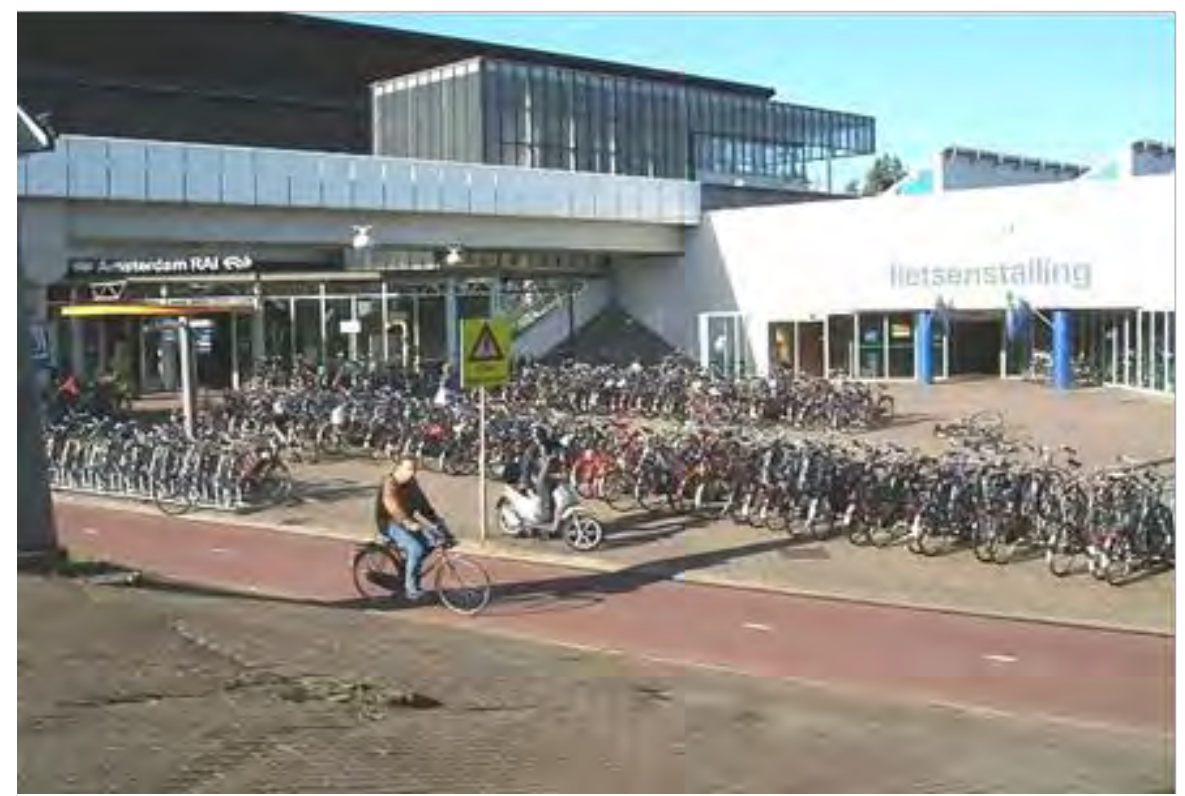

Figura 17. Estación de cercanías cerca de Amsterdam. Fietsenstalling: consigna de bicicletas.

Así pues la bicicleta, sola o en combinación con el transporte público, podría tener un papel de primer orden en la reorientación de la movilidad de la corona metropolitana hacia pautas más sostenibles. Para ello sería preciso desarrollar tanto una red de vías ciclistas que conectara los principales puntos de generación y atracción de viajes, como sistemas de intermodalidad bicicletatransporte público.

\section{Reflexiones finales}

La ciudad de Sevilla ha venido desarrollando a lo largo de los últimos años unas políticas de fomento de la movilidad en bicicleta con un éxito sin precedentes a escala mundial. Estas políticas se han basado en la creación de una red de vías ciclistas con un total de $120 \mathrm{~km}$ de vías bidireccionales segregadas y con carácter de viario estructurante de la ciudad, que conectan los principales centros de generación y atracción de viajes de la misma. Pasados apenas unos años de inicio de las obras, podemos decir que la bicicleta se ha convertido en una de las señas de identidad de la ciudad, con una participación en el reparto modal en torno al $6 \%$ del total de los desplazamientos urbanos y un crecimiento del orden del $1000 \%$ [sic] en el número de usuarios.
Entre los factores que han favorecido el éxito de estas políticas, que hoy en día se han convertido en un caso de estudio a nivel internacional ${ }^{23}$ cabe citar los siguientes:

- La creación de una red y no de vías ciclistas aisladas contribuyó a que los usuarios potenciales percibieran su utilidad desde el principio, evitando el conocido efecto desincentivador de las vías ciclistas que no se usan porque "van de ningún sitio a ninguna parte".

- Las vías ciclistas se realizaron como un proyecto singular, y no vinculadas a otras actuaciones. Esto facilitó tanto el diseño unificado de las mismas como la rapidez de ejecución de las obras que, como veremos mas abajo, fueron también factores determinantes del éxito.

- Las vías ciclistas se realizaron por las principales avenidas de la ciudad ya que los ciclistas -actuales y potenciales- tienen tendencia a circular por donde circula el resto de los ciudadanos.

- Las vías ciclistas se diseñaron según criterios

\footnotetext{
${ }^{23}$ La red de vías ciclistas de Sevilla obtuvo la calificación de "Best" en el octavo Concurso Internacional de Buenas prácticas de Naciones Unidas, celebrado en Dubai en 2010.
} 
de máxima seguridad y totalmente segregadas del tráfico motorizado. Esto también contribuyó a animar a los ciclistas potenciales a utilizarlas.

- Las obras se realizaron con rapidez: la red básica, de 77 km, se completó en poco más de un año; y la red completa, de 120 km, estuvo lista para su uso en apenas 4 años. Esta rapidez de ejecución contribuyó a dotar a las vías ciclistas de una utilidad evidente y de un alto nivel de uso desde el principio, contrarrestando así las molestias derivadas de las obras y el escepticismo de parte de la opinión pública acerca de su utilidad real.

- La red contó con un diseño unificado y muy visible. Esto también contribuyó a que la ciudadanía percibiera su presencia y la usara.

- La bicicleta pública contribuyó al éxito de la iniciativa, al permitir el acceso cómodo y rápido al sistema de movilidad ciclista de amplios sectores de la población, muchos de los cuales se incorporaron luego a la bicicleta privada.

- Se creó un órgano de gestión unificado: la Oficina de la Bicicleta.

- Se generó desde el principio un consenso con las asociaciones de usuarios y se fomentó su participación en el proceso, mediante la creación de la Comisión Cívica de la Bicicleta.

- Se integraron las actuaciones pre-existentes, como los $12 \mathrm{~km}$ de vías ciclistas ya construidos, el sistema Bus-Bici o los parkings universitarios, conectándolos mediante la red de vías ciclistas.

En conjunto, el éxito de las políticas de promoción de la bicicleta en Sevilla demuestra cómo actuaciones decididas, con presupuestos comparativamente bajos en relación con otras obras públicas relacionadas con la infraestructura del transporte, pueden tener un gran impacto en la transformación de la movilidad urbana hacia pautas más sostenibles. Se demuestra también que la rapidez en la ejecución es un factor coadyuvante al éxito, en la medida en que contribuye a hacer evidente desde el principio la utilidad de las actuaciones. En cuanto a las polémicas generadas, estas son inevitables en cualquier actuación de calado que afecte a la ciudad consolidada, pero como ya hemos indicado, el diseño adecuado y la rapidez de ejecución son los elementos clave para superarlas con éxito.

Lamentablemente, la experiencia de Sevilla es todavía una experiencia aislada, no solo en Andalucía sino incluso en el contexto de su propia Área Metropolitana, que apenas si se ha visto influida en su corona exterior por el éxito de las actuaciones referidas, que se han limitado a su núcleo central. No obstante, la bicicleta -por sí sola o en combinación con el transporte público- tiene también un enorme potencial de uso en la corona metropolitana de Sevilla. Desarrollar este potencial será clave para el éxito a largo plazo del proceso estudiado, así como para la transformación de las pautas de movilidad metropolitana hacia modelos más sostenibles. En particular, el fomento de la intermodalidad bicicleta-transporte público será probablemente una de las piedras angulares de esa transformación.

\section{Referencias}

A CONTRAMANO. El carril-bici de La Palmera dos años después. Ed. A Contramano, Asamblea ciclista de Sevilla, 2002. <http://www.acontramano.org/antigua/qhacemos /campa/memoria.pdf>. (Consultado el 12 de septiembre de 2012).

A CONTRAMANO. ¿Quitó el carril-bici espacio al peatón? Ed. A Contramano, Asamblea ciclista de Sevilla, 2008.

<http://www.acontramano.org/index.php?option= com_docman\&task=doc_download\&gid=7\&Itemi $\mathrm{d}=62>$. (Consultado el 12 de septiembre de 2012) 
A CONTRAMANO. Estructura de la movilidad y análisis de las políticas de transporte en el Área Metropolitana de Sevilla (1999-2011). Ed. A Contramano, Asamblea ciclista de Sevilla, 2011. <http://www.acontramano.org/index.php?option= com_docman\&task=doc_download\&gid=9\&ltemi $d=62>$. (Consultado el 12 de septiembre de 2012).

A CONTRAMANO. Vías ciclistas a nivel del acerado. Ed. A Contramano, Asamblea ciclista de Sevilla, 2011.

<http://www.acontramano.org/index.php?option= com_docman\&task=doc_download\&gid=8\&ltemi $d=62>$. (Consultado el 12 de septiembre de 2012).

AYUNTAMIENTO DE SEVILLA. Investigación sobre el uso de bicicletas en la ciudad de Sevilla y las demandas de los usuarios. G.M.U, Ayuntamiento de Sevilla, 2006.

<http://svqenbici.files.wordpress.com/2012/04/in vestigacion-uso-bicicletas-sep-2006.pdf >. (Consultado el 12 de septiembre de 2012).

AYUNTAMIENTO DE SEVILLA. Vías ciclistas de Sevilla. Dotaciones Equipamientos y Espacios Libres. G.M.U, Ayuntamiento de Sevilla, 2006. <http://svqenbici.files.wordpress.com/2012/04/in vestigacion-uso-bicicletas-jul-2007.pdf>. (Consultado el 12 de septiembre de 2012).

AYUNTAMIENTO DE SEVILLA. Desplazamientos en bicicleta en la red de vías ciclistas de Sevilla. Conteo en 42 puntos de observación. G.M.U, Ayuntamiento de Sevilla, 2008.

AYUNTAMIENTO DE SEVILLA. Estudio sobre el uso de la bicicleta en la ciudad de Sevilla. Gerencia de Urbanismo, Ayuntamiento de Sevilla, 2010.

<http://svqenbici.files.wordpress.com/2012/03/in vestigacion-uso-bicicletas-ene-2010.pdf>. (Consultado el 12 de septiembre de 2012).

CENTRO ANDALUZ DE PROSPECTIVA. Barómetros Socioeconómicos de Sevilla y otros es- tudios (2001-2011), Centro Andaluz de Prospectiva, 2007-2012.

<http://huespedes.cica.es/aliens/canp/frame_so cioeconomicos.html>. (Consultado el 12 de septiembre de 2012).

CITY OF CHICAGO. Bike 2015 Plan. City of Chicago, 2006.

<http://bike2015plan.org/pdf/bike2015plan.pdf>

CONSORCIO DE TRANSPORTES DEL ÁREA

DE SEVILLA. Encuesta domiciliaria de movilidad. Consorcio de Transportes del área de SeviIla, 2007.

$<$ http://www.consorciotransportessevilla.com/co municaciones/billeteunico/pdf/numero20.pdf>.

(Consultado el 12 de septiembre de 2012).

CONSORCIO DE TRANSPORTES DEL ÁREA DE SEVILLA. Bicicleta y Transporte Público en el Área Metropolitana de Sevilla. En VIII Congreso Ibérico La Bicicleta y la Ciudad. Sevilla, octubre de 2010.

$<$ http://www.acontramano.org/congreso/comisio nes/Consorcio_Transportes.pdf>. (Consultado el 12 de septiembre de 2012).

GERENCIA MUNICIPAL DE URBANISMO, Proyectos constructivos correspondientes a las redes básica y complementaria de carriles-bici de Sevilla y actuaciones posteriores: plan de mejora y extensión de la red en el marco del Programa "Ciudad 21". G.M.U, Ayuntamiento de Sevilla, 2005-2011.

MAIRIE DE PARIS, 2010-2014: Un coup d'accélérateur pour le vélo. Maririe de Paris, 2010. $<$ http://www.leparticulier.fr/upload/docs/applicati on/pdf/201005/plan_mairie_paris_26052010_pla n_velo_pistes_cyclables_paris.pdf>. (Consultado el 12 de septiembre de 2012).

MALPICA, Pedro. El carril-bici de Sevilla y los medios de comunicación: una aproximación a la proyección mediática del uso de la bicicleta en la capital andaluza. En VIII Congreso Ibérico La Bicicleta y la Ciudad. Sevilla, octubre de 2010. 
$<$ http://www.acontramano.org/congreso/comisio nes/pedro_malpica.pdf>. (Consultado el $12 \mathrm{de}$ septiembre de 2012).

MARQUÉS, Ricardo y HERNÁNDEZ, Vicente. La bicicleta en la Universidad de Sevilla - Informe anual 2009. SIBUS, Universidad de Sevilla, 2009.

<http://sostenibilidad.us.es/user/files/InformeSIB US_2009.pdf>. (Consultado el 12 de septiembre de 2012).

MOLINERO, Francisco, FERRANDO, Haritz, y RUIZ, Francisco José. Estudio comparado de la situación de la bicicleta como medio de transporte en 30 municipios españoles. CONBICI, Coordinadora en Defensa de la Bici. Barcelona, 2007.

<http://www.conbici.org/joomla/ciudades/estudio completo30ciudades.pdf>. (Consultado el 12 de septiembre de 2012).

NEW YORK CITY DEPT. OF CITY PLANNING. NYC Bicycle Master Plan. NYC Department of City Planning, New York, 1997.

<http://www.nyc.gov/html/dcp/pdf/bike/masterpl. pdf $>$. (Consultado el 12 de septiembre de 2012). SANZ, Alfonso, PÉREZ, Rodrigo, FERNANDEZ, Tomás. La bicicleta en la Ciudad. Ministerio de Fomento, Madrid, 1996.

\section{BLOGS Y PAGINAS WEB}

\section{Institucionales}

Ayuntamiento - Oficina de la Bicicleta: $<$ http://www.sevilla.org/sevillaenbici/>. (Consultado el 12 de septiembre de 2012).

Ayuntamiento - Sevici: <http://www.sevici.es/> Consorcio de Transportes - Bus-Bici:

$<$ http://www.consorciotransportessevilla.com/pro yectos/busbici/busbici.php>. (Consultado el 12 de septiembre de 2012).

Sistema Integral de la Bicicleta de la Universidad de Sevilla: <http://bicicletas.us.es/>. (Consultado el 12 de septiembre de 2012).

\section{Asociaciones y entidades:}

A Contramano: <http://www.acontramano.org >

Ciclofilia: <http://www.ciclofilia.org>. (Consultado el 12 de septiembre de 2012).

Blogs:

Carril-bici Sevilla: <http://www.carrilbicisevilla.es/> Sociedad Sostenible:

$<$ http://www.sociedadsostenible.com/>. (Consultado el 12 de septiembre de 2012).

Sevilla

en

bici:

$<$ http://sevillaenbici.blogspot.com/>. (Consultado el 12 de septiembre de 2012).

\section{Otros enlaces de interés:}

Ride the city - Sevilla (mapa interactivo de itinerarios ciclistas): <http://es.ridethecity.com/sevilla > Sevilla Cycle-chic (fotos):

$<$ http://www.sevillacyclechic.com/>. (Consultado el 12 de septiembre de 2012).

\section{Cita del artículo}

MARQUÉS SILLERO, R. Sevilla: una experiencia exitosa de promoción de la movilidad en bicicleta en el Sur de Europa. Hábitat y Sociedad, 2011, nº 3, p. 107130. <www.habitatysociedad.us.es>.

http://dx.doi.org/10.12795/HabitatySociedad.2011.i3.07 